\title{
BRUTO, QUINTO MUCIO E L'ABORTO PROVOCATO EX LEGE AQUILIA
}

\author{
Maria Virginia Sanna \\ Professora de Direito Romano e Direitos da Antiguidade \\ da Universidade de Caligari \\ mavisanna@alice.it
}

RIASSUNTO: Questo articolo intende discutere la teoria della dottrina dominante secondo il terzo capitolo della lex Aquilia che considera solo i "ceterae res". Nella più antica interpretazione della lex, infatti, Bruto non estende il "rumpere" agli schiavi e ai "pecudes", ma estende la nozione di "rumpere", prima legata agli schiavi e ai "pecudes", all'aborto. Bruto usa l'espressione "quasi rupto" perché non c'è contatto "corpore" con il feto, una cosa ronzante, mentre Q. Mucio usa "rumpere" perché, secondo lui, c'è un contatto "corpore" con l'equa, una cosa retta.

PAROLE CHIAVE: Aborto. Lex Aquilia. Dano. Rumpere.

\section{Brutus, Quinto Mucius e o aborto provocado ex lege aquilia}

RESUMO: Este artigo pretende debater a teoria da doutrina dominante de acordo com o terceiro capítulo da lex Aquilia considera apenas a "ceterae res". Na interpretação mais antiga da lex, de fato, Brutus não estende o "rumpere" aos escravos e "pecudes", mas estende a noção de "rumpere", antes relacionada aos escravos e pecudes, ao aborto. Brutus usa a expressão "quasi rupto" porque não existe um contato "corpore" com o feto, uma coisa ruptum, enquanto Q. Mucius usa "rumpere" porque, segundo ele, há um "corpore" de contato com o equa , uma coisa ruptuma.

PALAVRAS-CHAVE: Aborto. Lex Aquilia. Dano. Rumpere.

\section{Brutus, Quinto Mucius and the abortion provoked ex lege aquilia}

\begin{abstract}
This article intends to debate the theory of the dominant doctrine according to the third chapter of the lex Aquilia considers only the "ceterae res". In the most ancient interpretation of the lex, in fact, Brutus doesn't extend the "rumpere" to slaves and "pecudes", but extends the notion of "rumpere", before related to slaves and "pecudes", to abortion. Brutus uses the expression "quasi rupto" because there isn't a contact "corpore" with the fetus, a ruptum thing, while Q. Mucius uses "rumpere" because, according to him, there is a contact "corpore" with the equa, a ruptum thing.
\end{abstract}

KEYWORDS: Abortion. Lex Aquilia. Damage. Rumpere

1. Il problema della rilevanza dell'aborto provocato ad una cavalla (o a una schiava) ex lege Aquilia è affrontato da due giuristi repubblicani, i cui pareri sono riportati da Ulpiano e da Pomponio in: Ulp. 18 ad ed. D. 9, 2, 27, 22: Si mulier pugno vel equa ictu a te percussa eiecerit, Brutus ait Aquilia teneri quasi rupto Pomp. 17 ad Q. Muc.: D. 9, 2, 39 pr.: Quintus Mucius scribit: equa cum in alieno pasceretur, in cogendo quod praegnas erat eiecit: quaerebatur, do- 
minus eius possetne cum eo qui coegisset lege Aquilia agere, quia equam in iciendo ruperat. $\mathrm{Si}$ percussisset aut consulto vehementius egisset, visum est agere posse ${ }^{1}$

Per Bruto, afferma Ulpiano, si sarà tenuti ex lege Aquilia quasi rupto se una schiava o una cavalla, pregnantes, percosse la prima pugno la seconda ictu ${ }^{2}$, espellono il feto; per Quinto Mucio, riferisce Pomponio, il dominus di una cavalla praegnas - che pascolando su un fondo altrui e venendo da questo scacciata avesse espulso il feto - poteva agire ex lege Aquilia cum eo qui coegisset, ma solo se la cavalla era stata percossa o scacciata consulto con più veemenza del necessario.

Mentre Quinto Mucio, che scrive una cinquantina d'anni dopo Bruto, parla di ruptio della cavalla (quia equam in iciendo ruperat), Bruto utilizza il sintagma quasi rupto; non sembra, dunque, estendere il significato di rumpere sino a comprendervi il caso dell'aborto, probabilmente perché non era ancora giunto, diversamente da Quinto Mucio, ad intendere il rumpere come corrumpere, estensione, pure, dovuta ai veteres secondo il noto

- Ulp. 18 ad ed. D. 9, 2, 27, 13: Inquit lex ruperit. Rupisse verbum fere omnes veteres sic intellexerunt corruperit ${ }^{3}$.

1 Su cui da ultimo, A. CoRbINO, Lex Aquilia e procurato aborto, in Mélanges M. Humbert, Paris 2012, 159 ss.; Antigiuridicità e colpevolezza nella previsione del plebiscito aquiliano, in «SDHI» 75 (2009) $77 \mathrm{ss}$. Si veda anche, dello stesso autore, Danno, lesioni patrimoniali e lex Aquilia nella visione romana, in Filia, Scritti G. Franciosi, I, Napoli 2007, 607 ss.; Il dettato aquiliano, tecniche legislative e pensiero giuridico nella media repubblica, in Studi L Labruna, II, Napoli 2007, 1127 ss.; Il danno qualificato e la lex Aquilia 2 , Padova 2008; L'oggetto dell'aestimatio damni nella prospettiva del primo e del terzo capitolo del plebiscito aquiliano, in Studi R. Martini, I, Milano 2008, 699 ss.

2 Parla di abortus ictu anche per la schiava L. DE PINTO, Procurato aborto nei giuristi severiani, in «Koinonia» 37 (2013) 317 ss. L'autrice ritiene che da D. 9, 2, 27, 22 e D. 9, 2, 9 pr. si ricavi una conferma della "mancanza, per quell'epoca, di specifiche norme che elevassero il procurato aborto da illecito di carattere privato a illecito di carattere pubblico". Prendendo in esame sia testi concernenti l'aborto della schiava e della cavalla, sia testi concernenti l'aborto della donna libera, la De Pinto afferma che in entrambi i casi la preoccupazione riscontrabile sarebbe quella economica; l'idea non sembra condivisibile, dal momento che secondo la dottrina prevalente, cui l'autrice aderisce, il divieto di aborto nel caso della donna libera sarebbe dovuto all'esigenza di salvaguardare gli interessi del padre, interessi di natura certo non solo economica.

3 L'utilizzo del quasi ruptum potrebbe, peraltro, dipendere anche dalle peculiarità del caso dell'aborto; se infatti, come vedremo in seguito, l'oggetto della ruptio fosse il feto, anche intendendo rumpere come corrumpere, il feto non sarebbe corruptum. Se riteniamo, comunque, come a me pare più probabile, che Bruto non intendesse ancora il rumpere come corrumpere, egli non sarebbe tra i veteres di cui in D. 9, 2, 27, 13; d'altra parte Ulpiano usa l'avverbio fere, dunque non tutti i veteres intesero rumpere in tal modo. Per D. Daube, On the Third Chapter of the Lex Aquilia, in «LQR» 52 (1936) 253 ss., ora in Collected Studies in Roman Law I, Frankfurt am Main 1991, 3 ss., citato da Collected Studies, 5, il responso di Bruto in D. 9,2,27,22 e quello di Quinto Mucio in D. 9, 2, 39 pr., concernenti la causa di un aborto, mostrano che l'offesa non compresa sotto urere e frangere rientrava nella più ampia concezione di rumpere. Per G. Mac Cormack, Aquilian Studies, in «SDHI» 41 (1975) 43 ss., se si deve prendere alla lettera l'affermazione di Ulpiano per cui presso fere omnes veteres il verbo rumpere era inteso come corrumpere, se ne potrebbe dedurre che la maggioranza dei giuristi avrebbe esteso il significato di rumpere tanto da includervi il corrumpere, mentre altri avrebbero ristretto l'estensione di rumpere a situazioni che dovevano essere classificate come quasi rumpere. Secondo Mac Cormack è però possibile che Ulpiano abbia definito corrumpere ciò che i più antichi giuristi definirono quasi rumpere, oppure ancora è possibile che "the early jurists held that certain states of affairs constitued rumpere and did not differentiate them in terms of quasi rumpere or corrumpere. These states of affairs my have been ones which a later jurist would have included under corrumpere". Osserva D. Manfredini, Contributi allo studio dell'iniuria in età repubblicana, Milano 1979,56 , che se è vero che i giuristi classici attribuivano ai veteres il significato di rumpere come corrumpere, probabilmente alludevano ai giuristi della tarda repubblica per i quali effettivamente è provata la tendenza a interpretare rumpere come danneggiare, tendenza non da tutti seguita (fere omnes veteres D. 9, 2, 27, 13); ciò in ogni caso, documenterebbe, per l'autore, il fatto che rumpere aveva un valore più ristretto rispetto a quello di danneggiare. Se Bruto, mirando ad estendere la tutela aquiliana al caso dell'aborto procurato alla schiava, qualifica il fatto come quasi ruptio, vuol dire che ai suoi tempi rumpere non significava danneggiare. Per A. Bignardi, Frangere e rumpere nel lessico normativo e nella interpretatio prudentium, in Nozione formazione e interpretazione del diritto dall'età romana alle esperienze moderne, Ricerche F. Gallo, I, Napoli 1997, 11 ss., in part. 39, è difficile pensare che i veteres siano giunti ex abrupto all'equivalenza di rumpere come corrumpere, ma è possibile che a tale risultato siano arrivati in seguito ad un processo di graduale interpretazione ed elaborazione 
Bruto fu probabilmente pretore nel 142 a.C. ${ }^{4}$, Quinto Mucio console nel 955; dal momento che ci troviamo davanti alle prime testimonianze dell'attività interpretativa della lex Aquilia6, per una loro corretta lettura è forse utile soffermarsi preliminarmente sulla datazione della lex.

Accettando la datazione tradizionale del 286 a. C. ${ }^{7}$, il responso di Bruto riferito da U1piano si collocherebbe a 140/150 anni dalla sua emanazione; buona parte della dottrina ha, peraltro, messo in discussione tale datazione, che si basa sulla Parafrasi di Teofilo 4, 3, 15 ${ }^{8}$, in cui si ricorda una $\delta ı \alpha ́ \sigma \tau \alpha \sigma ı \varsigma$ fra plebe e Senato e su uno scolio ad Bas. 60, 3, 1, 4, in cui si tratta

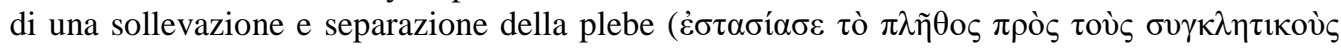

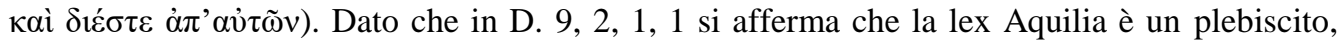
emanato quando era tribuno delle plebe Aquilio, che delle tre secessioni della plebe di cui si ha notizia una è del 494, una del 449, una del 286, l'unica data plausibile sarebbe quella del 286 a.C., che coincide con l'approvazione della lex Hortensia, con cui si stabilì che i plebisciti avessero valore di legge ${ }^{9}$.

dell'ambito di applicazione della previsione legislativa. I. Piro, Damnum corpore suo dare rem corpore possidere, L'oggettiva riferibilità del comportamento lesivo e della possessio nella riflessione e nel linguaggio dei giuristi romani, Napoli 2004, 23, ritiene che nella risalente testimonianza di Bruto si possa già ravvisare traccia del processo, frutto dell'interpretatio giurisprudenziale, che avrebbe determinato l'estensione, ad opera dei veteres, di rumpere in corrumpere, inteso come espressivo di ogni definitiva alterazione - materiale o funzionale - delle caratteristiche economiche della cosa. Per A. Franciosi, Il problema delle origini del plebiscito aquilio. Una messa a punto in tema di datazione, in Filia, Scritti G. Franciosi, II, Napoli 2007, 935 ss., in part. 949 nt. 51, l'intervento interpretativo di Bruto in D. 9, 2 ,27, 22 estende il significato di rumpere. Da ultimo per G. Valditara, In tema di stima del danno aquiliano, in «Index» 44 (2016) 197 ss., in part. 206, l'uso di quasi da parte di Bruto è significativo dello sforzo di ricondurre l'aborto entro il concetto di rumpere e quindi l'uccisione del feto ad un danneggiamento rilevante ex capite tertio del corpo della madre: si doveva presupporre che il corpo della madre fosse stato danneggiato attraverso una considerazione della uccisione del feto come ruptio.

4 Ma per F. SCHULZ, Roman Legal Science, Oxford 1953, 47, in data incerta; per V. GIUFFRÈ, La traccia di Quinto Mucio, Napoli 1993, 18, nel 142 o 140.

5 Si vedano A. Schiavone, Nascita della giurisprudenza, Bari 1976, 7 nt. 3; ID., Linee di storia del pensiero giuridico romano, Torino 1994, 48; GIUFFRÈ, La traccia di Quinto Mucio, cit., 22 nt. 20.

6 Secondo M. F. CURSI, Iniuria cum damno, Antigiuridicità e colpevolezza nella storia del danno aquiliano, Milano 2002, 165 nt. 71, non è necessario arrivare al responso di Bruto per fissare un termine ante quem per la lex Aquilia.

7 Datazione proposta da A. PERNICE, Zur Lehre von den Sachbeschädigungen nach römischen Recht, Weimar 1867, $11 \mathrm{ss}$.

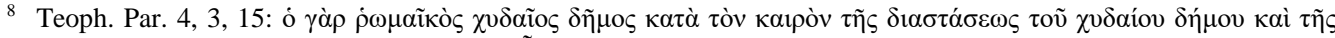

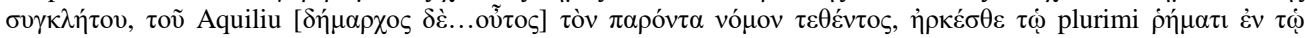
$\pi \rho \omega ́ \tau \varphi \kappa \varepsilon \uparrow \varepsilon \varepsilon v \omega \kappa \varepsilon \varphi \alpha \lambda \alpha \iota \varphi$ (plebs enim romana, cum tempore dissensionis inter plebem et patres Aquilius hanc legem rogaret, contenta fuit, quod prima parte id verbum plurimi positum esset).

9 Per A. BiscARDI, Sulla data della lex Aquilia, in Scritti A. Giuffré, I, Milano 1967, 77 ss., già prima della lex Hortensia le deliberazioni dei concilia plebis potevano avere efficacia vincolante per tutto il popolo. L'autore ritiene che l'episodio nel corso del quale Teofilo parla dell'approvazione del plebiscito Aquilio fosse quello relativo alla rivolta del 342 a.C., il che troverebbe conferma in Gai. 4, 37, in quanto la fictio civitatis prevista nelle ipotesi di furtum e damnum avrebbe senso solo in un periodo in cui i peregrini non potevano essere parti nel processo romano, pertanto prima della creazione del praetor peregrinus. Se si era avvertita la necessità di estendere l'actio ex lege Aquilia anche agli stranieri, questa non solo sarebbe stata applicata in epoca anteriore al 242 a.C., ma doveva essere in vigore già da considerevole tempo. Ricorda A. GuARINO, La data della lex Aquilia, in «Labeo» 14 (1968) 120 s., ora in Pagine, III, Napoli 1994, 262 ss., che già F. SERRAO, La iurisdictio del pretore peregrino, Milano 1954, 41 ss., aveva, però, osservato che le actiones ficticiae di Gai 4,37 non presuppongono la procedura delle legis actiones ma quella per formulas; per l'autore la lex Aquilia, nel testo a noi noto attraverso Gaio e Ulpiano, sarebbe il frutto di una stratificazione di leggi successive, così come, in precedenza, ritenuto da V. ARANGIO-RUIZ, Responsabilità contrattuale in diritto romano, Napoli 1927, 237 nt. 1, per il quale il terzo caput potrebbe essere un complemento posteriore, rifuso dalla giurisprudenza nella vecchia legge come in un testo unico. 


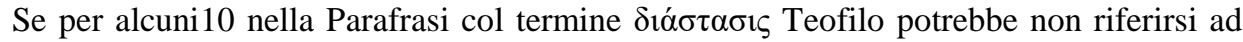
una secessione della plebe ma a semplici contrasti tra la plebe e il Senato, altri11, pur ritenendo ricavabile dal passo il collegamento con la secessione, pongono in evidenza che Teofilo era mosso dall'intento di giustificare l'assenza del termine plurimi nel terzo caput della lex, valutando se tale omissione nel plebiscito, atto votato dalla plebe nel corso della secessione, fosse frutto di una precisa volontà politica della stessa plebe ${ }^{12}$; anche l'accenno nello scolio dei Basilici ad una seditio non sarebbe ricollegabile espressamente alla lex Aquilia, ma servirebbe a spiegare il significato del termine plebiscito ${ }^{13}$. Confrontando il passo della Parafrasi con Gai $3,218^{14}$ e con le Istituzioni di Giustiniano ${ }^{15}$, si nota, osserva la Bignardi ${ }^{16}$, che Gaio e Sabino, a proposito dell'omissione nel terzo caput del termine plurimi, affermano che legis latorem contentum fuisse, quod prima parte eo verbo usus esset, mentre Giustiniano e Teofilo non parlano di legis lator ma di plebs ${ }^{17}$ : si sarebbe, probabilmente, enfatizzato il riferimento alla secessione per avvalorare l'idea che fosse stata la plebe ad accontentarsi di ottenere l'inserimento del plurimi nel primo caput. Per l'autrice l'improponibilità dell'indicazione di Teofilo risulta poi anche dal contenuto stesso della lex Aquilia; la maggioranza dei provvedimenti adottati dalle assemblee plebee - fatta eccezione per quelli di carattere più strettamente politico - riguardavano, infatti, la distribuzione delle terre e la riduzione dei debiti, ma la lex Aquilia, sanzionando i delitti contro i beni con l'obbligo di pagare al proprietario il maggior valore di quanto distrutto, dimostrerebbe "di essere un provvedimento assunto nell'interesse di una categoria di soggetti nella quale - all'epoca a cui il plebiscito viene tradizionalmente riferito - rientravano certamente tutti i patrizi, ma sicuramente non molti plebei", nonostante l'esistenza di famiglie plebee ricche. Non solo l'affermazione di Teofilo risulterebbe allora priva di senso comune, ma altrettanto infondata apparirebbe la datazione della legge in epoca così risalente.

\footnotetext{
${ }^{10}$ Per E. PAIS, Storia di Roma dalle origini all'inizio delle guerre puniche, I, 2, Torino 1899, 551 s. e ivi nt. 3, il conflitto non sarebbe tra patrizi e plebei ma tra popolo e Senato e potrebbe riguardare una delle sommosse dell'età graccana.

11 A. BignARDI, Theoph. Par. 4.3.15, ancora sulla data della lex Aquilia, in «AUFE» III (1989), $1 \mathrm{ss.}$

12 Osserva G. VAldiTARA, Damnum iniuria datum, in Derecho romano de obligaciones. Homenaje al Profesor José Luis Murga Gener, Madrid 1994, 825 ss.; Damnum iniuria datum², Torino 2005, 7, che Teofilo propone una spiegazione storica e non di tecnica legislativa. Per F. LA RosA, Il valore originario di iniuria nella lex Aquilia, in «Labeo» 44 (1998) 366 ss., in part. 370, l'accenno di Teofilo relativo all'emanazione della legge al tempo delle lotte fra patrizi e plebei costituisce una notizia troppo vaga.

${ }^{13}$ F. SERRAO, Uomini d'affari, adstipulatores, lex Aquilia alla fine del III secolo a.C., in Studi R. Martini, III, Milano 2009, 559 ss., ritiene che un'errata interpretazione aveva indotto larga parte degli studiosi a collegare lo scolio a quanto afferma Teofilo e ad attribuire a Teofilo e all'ignoto scoliasta la notizia che la legge sarebbe stata approvata su proposta del tribuno Aquilio in una fase di tensione fra plebe e Senato, anzi durante una secessione, collocando in tal modo nella secessione non l'origine del tribunato bensì il tribunato di Aquilio e il suo plebiscito sul danno ingiusto. Lo scolio dell'anonimo si limitava invece, per l'autore, a precisare ai lettori dei Basilici, promulgati ben undici secoli dopo, che cosa erano i plebisciti proposti dai tribuni, magistratura plebea creata durante una grande secessione della plebe dal senato, ossia durante la prima secessione del 494 a.C.

${ }^{14}$ Gai 3, 218: Ac ne 'plurimi'quidem verbum adicitur. Et ideo quidam putaverunt liberum esse iudici ad id tempus ex diebus $\mathrm{xxx}$ aestimationem redigere, quo plurimi res fuerit, vel ad id, quo minoris fuerit. Sed Sabino placuit proinde habendum, ac si etiam hac parte plurimi verbum adiectum esset; nam legis latorem contentum fuisse, <quod prima parte eo verbo usus esset>.

15 I. 4, 3, 14: Ac ne plurimi quidem verbum adicitur. sed Sabino <recte> placuit perinde habendam aestimationem, ac si etiam hac parte plurimi verbum adiectum fuisset: nam plebem Romanam, quae Aquilio tribuno rogante hanc legem tulit, contentam fuisse, quod prima parte eo verbo usa est.

16 Bignardi, Theoph. Par. 4.3.15, cit., 29 ss.

${ }^{17} \mathrm{Si}$ veda G. VALDITARA, Gai. 3,218 - I. 4,3,15 e l'evoluzione del concetto di legislator, in Nozione formazione e interpretazione del diritto dall'età romana alle esperienze moderne. Ricerche F. Gallo, II, Napoli 1997, 481 ss.
} 
Se le fonti che hanno portato a fissare come unica data possibile quella della secessione della plebe verificatasi nel 286 a.C. ${ }^{18}$ non sembrano, dunque, fornire una testimonianza univoca, non sono mancate proposte di datazioni meno risalenti: l'Honoré ${ }^{19}$, ritenendo comprensibile la pena variabile prevista dalla lex Aquilia solo in un periodo di forte inflazione, la colloca tra il 207 e il 195 a.C., alla fine della II guerra punica; per il Cannata $^{20}$, la lex è da attribuire all'epoca di Sesto Pedio e forse a Publio Aquilio, che deve essere stato tribuno della plebe nel 210 a.C.; anche il Serrao ${ }^{21}$, per il quale la lex Aquilia, "espressione di un'economia schiavistica piuttosto sviluppata", non può essere datata agli inizi del III secolo, in cui può ravvisarsi una fase di transizione "ma non ancora un'età in cui il modo di produzione schiavistico aveva acquistato forza e vigore" 22 , ritiene che l'autore della lex possa essere stato Publio Aquilio; sposta ancora più avanti la datazione il Birks ${ }^{23}$, il quale propone di fissare l'emanazione del plebiscito intorno al 140-125 a.C., in ogni caso prima della morte di Bruto. Collocare la lex Aquilia in un periodo così vicino a quello di Bruto non appare, a mio avviso, condivisibile, in quanto, se anche il giurista, utilizzando il sintagma quasi rupto non sembra estendere il significato di rumpere sino a comprendervi il caso dell'aborto, fa rientrare all'interno della categoria costituita dal verbo tipizzato rumpere una lesione in qualche modo assimilabile, che a prima vista non vi rientrerebbe. Maggiormente condivisibile appare una datazione nel III secolo, più probabilmente nella seconda metà. Si può ricordare a tal proposito che il Capogrossi aveva richiamato l'attenzione sulla circostanza che nel testo originario della lex Aquilia si usava la parola erus, come ricorda Ulpiano in 18 ad ed. D. 9, 2, 11, 6 (Legis autem Aquiliae actio ero competit, hoc est domino), indicando con erus perlomeno il proprietario di schiavi e animali ${ }^{24}$. Dall'esame dell'utilizzo dei termini erus e dominus nelle più importanti opere letterarie che vanno dalla fine del terzo alla metà del secondo secolo, quelle di Plauto, Terenzio e Catone, si riscontra, ha

${ }^{18}$ Di recente anche G. NICOSIA, Brevis Dominus, in Scritti G. Franciosi, III, Napoli 2007, 1847 ss., ritiene escluso che sulla base di Teofilo, Par. 4, 3, 15, e dello scolio 4 a Bas. 60, 3, 1, si possa far coincidere la data del plebiscito aquilio con quella della lex Hortensia de plebiscitis (287-286 a. C.)

19 T. HonORÉ, The Linguistic and Social Context of the Lex Aquilia, in «The Irish Jurist» 7 (1972) 145 ss.

${ }^{20}$ C. A. CANNATA, Sul testo originale della lex Aquilia: premesse e ricostruzioni del primo capo, in «SDHI» 58 (1992) 194 ss, ora in Scritti scelti di diritto romano, II, Torino 2012, 1 ss.; ID., Considerazioni sul testo e la portata originaria del II capo della lex Aquilia, in «Index» 22 (1994) 151 ss., ora in Scritti, II, cit., 119 ss.; Sul testo della lex Aquilia e la sua portata originaria in L. VACCA (a cura di), La responsabilità civile da atto illecito nella prospettiva storico comparatistica, Torino 1995, 25 ss., ora in Scritti, II, cit., 153 ss.; Il terzo capo della lex Aquilia, in «BIDR» 98-99 (1995-96) 111 ss., ora in Scritti, II, cit., 239 ss., in part. 260, citati dagli Scritti.

${ }^{21}$ SERraO, Uomini d'affari, cit., 563 ss.

22 La lex Aquilia fu probabilmente, per il Serrao, la prima "macroscopica espressione del modo di produzione schiavistico che prende atto dell'avvenuta reificazione degli schiavi e tratta la loro uccisione e il loro ferimento dal punto di vista del danno che da quei fatti illeciti deriva al loro proprietario". Si può infatti osservare, rileva l'autore, che mentre nelle XII Tavole la frattura dell'osso del servo è presa in considerazione insieme alla frattura del libero, con la sola differenza della minore pena pecuniaria (Tab. VIII.3), nella lex Aquilia il servus è preso in considerazione insieme alle pecudes.

${ }^{23}$ Per P. BIRKS, Doing and Causing to Be Done, in A.D.E. LewIS e D.J. IBBETSON (a cura di), The Roman Law Tradition, in Cambridge 1994, 32 ss., in part. 45, "the one secure fact which we know about the date of the lex is that it had been passed before the jurist Brutus died, since he gave an opinion on its scope. That means that it must have been passed by about $125 \mathrm{BC}$. Though most scholars do place it earlier, a case every bit as strong can be made for a date after the third Punic war, late in the 140 s." Per G.I. LuZZATTO, s.v. Colpa penale (diritto romano), in «ED», VII, Milano 1960, 614 ss.; G. CRIFò, s.v. Danno (Storia), in «ED», XI, Milano 1962, 615 ss., la lex Aquilia sarebbe da collocare in data anteriore al 130 a.C.

${ }^{24}$ In D. 9, 2, 27, 5, in cui per la dottrina dominante Ulpiano riporta le parole del terzo caput (vedi infra), utilizza dominus: tantum aes domino dare damnas esto; per parte della dottrina (v. ad es. VALDITARA, Damnum², cit., 51), il chiarimento relativo ad erus di D. 9, 2, 11, 6 riguarderebbe solo il commento al primo caput, per altra parte (F. GALLO, Potestas e dominium nell'esperienza giuridica romana, in «Labeo» 16 (1970) 17 ss., in part. 42 nt. 49), dato il tenore di D. $9,2,11,6$, è probabile che il termine erus fosse indicato anche nel terzo caput. Di questo avviso, di recente, E. TASSI SCANDONE, Erus...quod est dominus. Le nuove prospettive di indagine terminologica. Un primo bilancio, in «BIDR» 109 (2015) 141 ss. 
osservato il Capogrossi ${ }^{25}$, un fenomeno di decadimento di erus e il suo progressivo abbandono nell'uso corrente del latino: nelle commedie di Plauto erus è utilizzato in 368 casi, sempre riferito al proprietario di uno schiavo, di fronte ai soli 41 in cui è usato il termine dominus ${ }^{26}$; nelle commedie di Terenzio appare 52 volte di fronte alle 11 in cui viene usato dominus, in Catone non appare più impiegato ed è sostituito completamente da dominus ${ }^{27}$. Il Capogrossi aveva ritenuto in un primo tempo ${ }^{28}$ che l'utilizzo di erus nella lex Aquilia ad indicare il proprietario di schiavi e animali e in Plauto solo il proprietario di schiavi mostrerebbe un'accezione più ampia e dunque più antica della lex Aquilia, che dovrebbe quindi essere datata nella prima metà del III secolo ${ }^{29}$; in seguito ha però osservato ${ }^{30}$ che il collegamento di erus nella lex Aquilia con beni diversi dallo schiavo può essere stato occasionato dalla preminenza assunta dagli schiavi stessi ${ }^{31}$, per cui al rapporto primario erus-servus si sarebbero collegate

${ }^{25}$ L. CAPOGROSSI COLOGNESI, La struttura della proprietà e la formazione dei iura praediorum nell'età repubblicana, I, Milano 1969, 414 ss.; ID., Il campo semantico della schiavitù nella cultura latina del terzo e del secondo secolo a.C., in Studi Storici, XIX, 1978, 721.

${ }^{26}$ per 19 volte a indicare il proprietario di un bene diverso dallo schiavo: Asin. 2: quae quidem mihi atque vobis res vertat bene gregique huic et domino atque conductoribus, Capt. 809: eorum si quoiusquam scrofam in publico conspexero, ex ipsis dominis meis pugnis exculcabo furfures, 822: et petronem et dominum reddam mortales miserrumos; Cas. 722: ita quoquo adveniunt, ubi ubi sunt, duplici damno dominos multant; Mil. glor. 729: quae inprobast, pro mercis vitio dominum pretio pauperet; Most. 108: tempestas venit, confringit tegulas imbricesque: ibi dominus indiligens reddere alias nevolt, 661: sed nomen domini quaero quid siet, 686: aedium dominus foras; Poen. 535: quod tu invitus numquam reddas domino, de quoio ederis? Pseud. 1140: aedium dominum lenonem Ballionem quaerito, 1186: quid mercedis petasus hodie domino demeret? Quid, domino? quid somniatis? Mea quidem haec habeo omnia, meo peculio empta; Rud. 956: furtum ego vidi qui faciebat: noram dominum id quoi fiebat, 958a: nunc mihi si vis dare dimidium, indicium domino non faciam, 961a: nam, nisi dat, domino dicundum censeo, 965: et qui invenit hominem novi, et dominus qui nunc est scio, 969: non ferat, si dominus veniat? dominus huic, ne frustra sis, nisi ego nemo natust, hunc qui cepi in venatu meo, 1021: si veniat nunc dominus qouiust, ego qui inspectavi procul te hunc habere, fur sum quam tu? Trin. 177: an ego alium dominum patere fieri hisce aedibus?

${ }^{27}$ Per NiCOSIA, Brevis dominus, cit., 1847 ss., la tecnicizzazione nel linguaggio giuridico del termine dominus, ove opportuno con la specificazione ex iure Quiritium, per indicare il 'proprietario', è da considerare frutto dell'elaborazione giurisprudenziale volta a configurare appunto il concetto tecnico di 'proprietario', e da ricollegare al sorgere e rapido diffondersi dell'agere per formulas (e che corrisponde all'epoca in cui nei testi non giuridici emerge la progressiva diffusione dell'impiego di dominus).

${ }^{28}$ CAPOGROSSi COLOGNESI, La struttura, cit., 414 ss.

${ }^{29}$ Per CuRSI, Iniuria cum damno, cit., 248 ss., anche ammettendo che il valore di erus attestato nella lex Aquilia sia più arcaico di quello plautino, non si vede perchè, in assenza di altre fonti, dovrebbe ritenersi che la lex Aquilia sia non solo precedente le commedie di Plauto, ma addirittura da datare nella prima metà del III secolo. Concorda con la Cursi di recente S. GALEOTTI, Ricerche sulla nozione di damnum, I, Il danno nel diritto romano tra semantica e interpretazione, Napoli 2015, 86, la quale ritiene che la tesi del Capogrossi poggi 'su un'insuperabile tautologia', poiché domanda all'unica testimonianza pervenuta di un (possibile) più lato impiego di erus di collocarlo nel tempo.

${ }^{30}$ L. CAPOGRossi Colognesi, La denominazione degli schiavi e dei padroni nel latino del terzo e del secondo secolo a.C., in Actes du colloque sur l'esclavage, Warszawa 1979, 171 ss., in part. 187 nt. 14, ora in Scritti scelti L. Capogrossi, II, Napoli 2010, 739 ss.

31 Per F. BEER, Dominus e erus, in «Diritto e storia» 10 (2012) passim, la circostanza che in Terenzio, autore collocabile pochi decenni dopo Plauto, erus ricorra cinquantadue volte e dominus sia, invece, utilizzato in undici circostanze, mostra come in pochi decenni il vocabolo dominus inizi a essere impiegato in maniera molto più ampia, secondo una linea di tendenza che sembra confermata dalle fonti coeve, ma anche immediatamente successive al periodo storico preso in esame, dal momento che già Catone utilizza unicamente il termine dominus e mai erus. Per il Beer il passaggio dal termine erus a dominus potrebbe essere spiegato attraverso la lenta e progressiva evoluzione dei concetti di familia e di persona, e con essi di una diversa impostazione dei rapporti di potere fra pater familias e dominus. Nell'antichità romana il potere di diritto che oggi definiamo proprietà era generalmente concepito come rapporto di natura (o di prioritaria rilevanza) familiare poiché la vita sociale si concentrava fortemente all'interno dell'aggregato familiare. Con il passare del tempo, anche in coincidenza del lento affermarsi di una nuova giurisprudenza dalla metà del II secolo a.C., si diffonderebbe l'utilizzo del termine dominus anche per riferirsi al proprietario del servus; in questo stesso periodo si evidenzia anche una prima tendenza a differenziare a livello terminologico anche il potere di diritto (dominium ex iure Quiritium) dal 'potere di fatto' che era assegnato dal pretore. In questa maniera sembra svolgersi, per il Beer, il lento e progressivo passaggio verso una terminologia che sarà poi consueta e, si può dire, consolidata certamente nel II secolo d.C. 
altre relazioni in forma subordinata ${ }^{32}$. Verrebbe meno, pertanto, il motivo per una datazione nella prima metà del III secolo, così come, in seguito alle osservazioni della Cursi, sembrano venuti meno anche i motivi per la datazione agli inizi del III secolo proposta dal Nörr ${ }^{33}$ sulla base dell'idea, invero non probante ${ }^{34}$, che il verbo occidere venga utilizzato da Plauto in senso più ampio rispetto alla lex Aquilia. Nello Pseudolus, la cui prima rappresentazione risale plausibilmente al 191 a.C., Plauto farebbe quasi una parodia della lex Aquilia, ponendo sullo stesso piano l'occidere gladio e il fames occidere, con un'estensione più ampia rispetto all'interpretazione aquiliana, che originariamente contrapponeva occidere (causalità diretta) e causam mortis praestare (causalità indiretta) ${ }^{35}$. Dall'utilizzo in Plauto dell'espressione fames occidere si ricaverebbe, per il Nörr, il superamento ermeneutico del primo valore legale del verbo occidere

- Pseud. 349: Eho, Pseudole, ei, gladium adfer. Quid opus $<\mathrm{t}>$ gladio? Qui hunc occidam atque me. Quin tu te $<\mathrm{d}>$ occidis potius? nam hunc fames iam occiderit

Nella commedia il giovane Calidoro, innamorato di Fenicia, schiava del lenone Ballione, per il cui riscatto ha promesso venti mine, che però non è riuscito a trovare ${ }^{36}$, alla notizia che il lenone ha venduto la ragazza a un soldato macedone chiede allo schiavo Pseudolo di portargli una spada per uccidere Ballione e se stesso, ma Pseudolo gli consiglia di uccidere solo se stesso perchè sarà la Fame ad uccidere Ballione. Per la Cursi ${ }^{37}$ il Nörr non coglierebbe pienamente nel segno proponendo una costruzione speculare all'ablativo strumentale per la locuzione fames occidit: è la Fame ad uccidere Ballione (fames occiderit, al nominativo) 'in un rapporto di causalità diretta', e non Ballione a morire di fame, 'secondo un nesso di causalità

32 Per FRANCIOSI, Il problema, cit., 958 ss., dal momento che nella lex Aquilia il significato di erus è quello di proprietario di schiavi e bestiame (e meno probabilmente anche di altri beni), che in Plauto compare soprattutto in riferimento al padrone dello schiavo, mentre in Terenzio come perfetto sinonimo di dominus, in un'accezione più ampia, si dovrebbe propendere per una datazione all'incirca nell'epoca di transizione tra l'attività di Plauto e quella di Terenzio, ossia nel periodo a cavallo tra la fine del III e il principio del II sec. a.C. Anche il cauto linguaggio di Bruto, il quale si esprime in termini di quasi ruptio, ove il quasi denoterebbe una certa timidezza nell'estensione interpretativa, si attaglia, per l'autrice, ad un'epoca relativamente prossima a quella dell'approvazione della legge.

33 D. NöRR, Causa Mortis: Auf den Spuren einer Redewendung, München 1986, 127 s. e nt. 26; ID., Texte zur lex Aquilia, in Iuris professio, Festgabe für M. Kaser, Wien, Köln, Graz 1986, 211 ss.

${ }^{34}$ Sembra, invece, accoglierla VALDITARA, Damnum ${ }^{2}$, cit., 6 e ivi nt. 32.

35 Per Nörr nell'ambito dell'interpretazione della lex Aquilia si sarebbe utilizzata l'espressione causam mortis praestare per tutti quei casi di causalità mediata per i quali si doveva esperire, nel processo formulare, un'actio in factum $\mathrm{o}$ utilis. Si veda ad esempio il noto Ulp. 18 ad ed. D. 9, 2, 7, 6: Celsus autem multum interesse dicit, occiderit an mortis causa praestiterit, ut qui mortis causa praestitit, non Aquilia, sed in factum actione teneatur. unde adfert eum qui venenum pro medicamento dedit et ait causam mortem praestitisse, quemadmodum eum qui furenti gladium porrexit: nam nec hunc lege Aquilia teneri, sed in factum.

${ }^{36} \mathrm{O}$ meglio ha dato un acconto di quindici mine con l'accordo di consegnare le altre cinque entro una certa data. Si discute, peraltro, in dottrina se Plauto intendesse riferirsi al contratto arrale greco o al contratto consensuale romano, dal momento che, come è noto, le commedie di Plauto sono tratte da modelli greci, il che aveva portato, in tempi passati, buona parte della dottrina a negare la possibilità dell'utilizzazione degli scritti del comico per la conoscenza del diritto e della società nel suo tempo. In tal senso, tra una bibliografia sterminata, ci limitiamo a ricordare i fondamentali studi di E. Fraenkel, Elementi plautini in Plauto, trad. it. F. MunARI, Firenze 1960 e di U.E. PAOLI, Comici latini e diritto attico, Milano 1962. Diversamente la dottrina più recente, così, tra gli altri, $M$. V. Giangrieco Pessi, Argentarii e trapeziti nel teatro di Plauto, in «A.G.» 201 (1981) 39 ss.; G. FALCONE, Testimonianze plautine in tema di 'interdicta', in «AUPA» 40 (1988) 182 ss.; C. VENTURINI, Plauto come fonte giuridica: osservazioni e problemi, in AA.VV., L. AGOSTINIANI, P. DESIDERI (a cura di), Plauto testimone della società del suo tempo, Napoli 2003, 114 ss.; CURSI, Iniuria cum damno, cit., passim; M.V. BRAMANTE, Patres filii e filiae nelle commedie di Plauto. Note sul diritto nel teatro, in E. CANTARELla, L. GAGLIARDI (a cura di), Diritto e teatro in Grecia e a Roma, Milano 2007, 95 ss.; S. CRISTALDI, Diritto e pratica della compravendita nel tempo di Plauto, in «Index» 39 (2011) 491 ss.; L. PELleCCHI, Per una lettura giuridica della Rudens, Pavia 2012.

${ }^{37}$ CURSI, Iniuria cum damno, cit., 157 ss. 
mediata $^{38}$. Sarebbe proprio Plauto, contrariamente a quanto sostenuto dal Nörr, ad offrire, invece, una testimonianza "per ritenere distinte, almeno ancora agli inizi del II sec. a.C., le aree semantiche dell'occidere e del causam mortis praestare". L'osservazione della Cursi è condivisibile, anche se sembra forse eccessivo parlare di una 'sofisticata costruzione plautina': Plauto, che pur conosce e ricorda correttamente molti istituti giuridici, sembra utilizzare a proposito degli eventi causativi di morte verbi diversi senza attribuire loro un preciso significato tecnico: nello Pseudolus, come visto, utilizza l'espressione fames occiderit, nell'Asinaria ne nos moriamur fame ${ }^{39}$, nella Persa ne enices fame ${ }^{40}$, nella Cistellaria exponendam ad necem per indicare la morte che segue all'esposizione ${ }^{41}$, ma nelle Bacchides ut necem per l'uccisione (cruenta) minacciata dal soldato nel caso scoprisse l'amata con l'altro uomo ${ }^{42}$, utilizzando, dunque, necare con un significato differente rispetto a quello di morte sine ictu ${ }^{43}$. Pur non essendo possibile ricavare da questi elementi una datazione certa della lex Aquilia, sembra preferibile, a mio avviso, una collocazione nella seconda metà o più specificamente verso la fine del III secolo; in tal caso, il minor lasso di tempo intercorrente tra l'emanazione della lex e l'opera di Bruto potrebbe spiegare il motivo per cui il giurista repubblicano non attribuisse al rumpere un significato così esteso da ricomprendervi il caso dell'aborto, mentre con Quinto Mucio, che opera presumibilmente dopo una cinquantina d'anni, l'evoluzione giurisprudenziale fosse, invece, giunta a vedere il rumpere come corrumpere, e dunque nell'aborto una corruptio della cavalla. Ma se anche ritenessimo che la lex fosse stata emanata in precedenza, all'inizio o nella prima metà del III secolo, non mi pare esistano prove del fatto che al tempo di Bruto, fundator, come è noto, insieme a Manilio e Scevola, del ius civile, la giurisprudenza in tema di lex Aquilia avesse già raggiunto un elevato grado di evoluzione, come ritiene parte della dottrina ${ }^{44}$.

2. Per il Cannata, che ritiene plausibile, come abbiamo visto, una datazione della lex intorno al 210/200, il dettato originario del terzo caput avrebbe riguardato solo la distruzione delle ceterae res, esclusi schiavi e pecudes ${ }^{45}$. Dal momento che nel passo di Bruto, primo testo

${ }^{38}$ Per FRANCIOSI, Il problema, cit., 955 ss., se da un punto di vista logico la ricostruzione del Nörr può sembrare lineare, di fatto le conclusioni cui approda la fanno apparire tautologica: si parte dal presupposto della risalenza della legge per tornare allo stesso concetto, attraverso l'analisi del valore di occidere nella legge stessa e nell'interpretazione giurisprudenziale.

39 Asin. 531: dum eius exspectamus mortem, ne nos moriamur fame.

${ }^{40}$ Persa 317: Qui boves bini hic sunt in crumena. Emitte sodes, ne enices fame; sine ire pastum.

${ }^{41}$ Cist. 166: dat eam puellam ei servo exponendam ad necem.

${ }^{42}$ Bacch. 859 s.: Nihil est lucri quod me hodie facere mavelim, quam illum cubantem cum illa opprimere, ambo ut necem.

${ }^{43}$ Il significato di necare come morte sine ictu (Fest. s.v. Neci datus: proprie dicitur, qui sine vulnere interfectus est ut veneno aut fame) potrebbe essere stato già utilizzato nelle XII Tavole: Cic. de leg. 3, 8, 19: cito [necatus] tamquam ex XII tabulis insignis ad deformitatem puer (Tab. IV.1). Per B. AlBANESE, Appunti su XII Tab. 4.1 (Uccisione dei neonati deformi), in Melanges Sturm, I, Liege 1999, 3 ss., vi sono, infatti, serie possibilità che si tratti dei resti testuali del versetto decemvirale conservato nella tradizione nota a Cicerone; la lettura cito necatus, proposta da Pierre Dupuy, e seguita dalla maggior parte dei moderni editori del de legibus, è, per l'autore, avvalorata dal fatto che le locuzioni connesse a nex sono applicate specificamente all'uccisione non cruenta, e sembra assai probabile che secondo l'antico diritto e i mores la soppressione dei neonati deformi dovesse essere realizzata in modo non cruento.

${ }^{44} \mathrm{Si}$ vedano U. Von LuBTOw, Untersuchungen zur lex Aquilia de damno iniuria dato, Berlin 1971, 17: "Unter seinen interpreten befindet sich M. Iunius Brutus (Ulp. D. 9, 2, 27, 22) de rum die Mitte des zweiten vorchristilichen Jahrhunderts lebte. Das Gesetz ist damals schon durch Auslegung fortgebildet; es mu $\beta$ also bereits geraume Zeit gegolten habet"; CORBINO, Il danno qualificato ${ }^{2}$, cit., 62, per il quale con la soluzione prospettata in D. 9, 2, 27, 22 Bruto presuppone come già in corso al suo tempo un'apertura interpretativa che avrebbe portato all'affermarsi (già ad opera dei veteres) dell'idea di attribuire al rumpere il significato onnicomprensivo di corrumpere.

45 CANNATA, Il terzo capo, cit., 239 ss., ritiene, infatti, seguendo una tesi proposta a suo tempo da H. F. JOLOWICZ, The Original Scope of the Lex Aquilia and the Question of Damages, in «LQR» 38 (1922) 220 ss., che la lex Aquilia prevedesse al terzo caput solo fatti dannosi che producessero la perdita delle ceterae res. In senso contrario VALDITARA, Damnum² ${ }^{2}$ cit., 14 ss., per il quale accettando la tesi del Cannata si dovrebbe concludere che nella lex Aquilia era prevista una sanzione per la ruptio o la fractio di bestiame minuto ma non di quadrupede da gregge. A parte l'incongruenza di una conclusione siffatta, soprattutto se rapportata con il contenuto del capo I, non è pensabile, per 
a noi giunto di interpretazione della lex Aquilia, si prendono in considerazione una schiava e una pecus, cioè proprio quei beni che secondo la tesi del Cannata sarebbero in origine esclusi dall'applicazione del terzo caput, all'epoca di Bruto, in un lasso di tempo di soli cinquant'anni, si sarebbe già compiuta quell'evoluzione giurisprudenziale che avrebbe portato, per l'autore, ad ampliare l'ambito del terzo caput dalla distruzione delle ceterae res al deterioramento di tutti i beni, compresi schiavi e pecudes. Il Cannata ritiene che tale evoluzione potè essere compiuta solo da giuristi "ormai convinti che con l'interpretatio si potesse costruire diritto nuovo anche rispetto alle leggi, e capaci di farlo", dai fundatores, e per la precisione da Marco Giunio Bruto, ma a me pare che il giurista in D. 9, 2, 27, 22 non intenda estendere l'ambito di applicazione del terzo caput della lex Aquilia a schiavi e pecudes, quanto piuttosto estendere la portata del verbo rumpere, già relativo alla mulier e all'equa, al caso dell'aborto: al momento dell'emanazione della lex, la tipicità dei verbi urere frangere rumpere doveva, infatti, essere assoluta, ma ben presto si dovette manifestare l'esigenza di un allargamento delle fattispecie in essi comprese, e rumpere era il verbo che meglio si prestava a questo scopo, o dal punto di vista dell'assimilazione, come sembra fare Bruto (quasi ruptum, è come se fosse rotto), o, in seguito, da un punto di vista semantico (rumpere come corrumpere). Bruto in D. 9, 2, 27, 22 dà per scontato che si possa parlare di rumpere riguardo alla schiava e alla cavalla, preoccupandosi piuttosto di farvi rientrare anche il caso dell'aborto; se fosse stato il primo a tentare di estendere attraverso l'interpretatio l'ambito di applicazione del terzo caput dalla distruzione delle ceterae res al danneggiamento di tutti i beni, compresi schiavi e pecudes, difficilmente si sarebbe espresso in tal modo.

Appare necessario, allora, esaminare le fonti che ci sono pervenute sull'ambito di applicazione del terzo caput della lex Aquilia, per verificare se avvalorano l'idea che schiavi e pecudes non vi fossero ricompresi:

- Gai 3, 217-18: Capite tertio de omni cetero damno cavetur. Itaque si quis servum vel eam quadrupedem quae pecudum <numero est vulneraverit, sive eam quadrupedem quae pecudum> numero <non> est, veluti canem, aut feram bestiam, veluti ursum leonem, vulneraverit vel occiderit, hoc capite actio constituitur. In ceteris quoque animalibus, item in omnibus rebus quae anima carent damnum iniuria datum hac parte vindicatur. Si quid enim ustum aut ruptum aut fractum <fuerit>, actio hoc capite constituitur, quamquam potuerit sola rupti appellatio in omnes istas causas sufficere; ruptum <enim intellegitur quod quoque modo corruptum> est. Unde non solum usta [aut rupta] aut fracta, sed etiam scissa et conlisa et effusa et quoque modo vitiata aut perempta atque deteriora facta hoc verbo continentur. Hoc tamen capite non quanti in eo anno, sed quanti in diebus XXX proximis ea res fuerit, damnatur is qui damnum dederit. Ac ne plurimi quidem verbum adicitur. Et ideo quidam putaverunt liberum esse iudici ad id tempus ex diebus $\mathrm{XXX}$ aestimationem redigere, quo plurimi res fuerit, vel ad id quo minoris fuerit. Sed Sabino placuit proinde habendum, ac si etiam hac parte plurimi verbum adiectum esset; nam legis latorem contentum fuisse <quod prima parte eo verbo usus esset>

- Ist. 4, 3, 13-15: Capite tertio de omni cetero damno cavetur. Itaque si quis servum vel eam quadrupedem quae pecudum numero est vulneraverit, sive eam quadrupedem quae

l'autore, che non fosse prevista una tutela per il danneggiamento di servi e quadrupedi o che detto illecito fosse regolato da un regime singolare. Inoltre non si comprenderebbe, in tal caso, il riferimento per la determinazione della pena al mese, che, se appare speculare all'anno, presupponendo un'ipotesi di minore gravità quale il ferimento del servo rispetto alla sua uccisione, non ha alcun senso per la gran parte dei beni restanti, il cui valore non doveva subire normalmente variazioni stagionali. Il periodo di trenta giorni si spiega, secondo il Valditara, per i casi in cui il servo potesse ristabilirsi con la necessità di avere riguardo nella valutazione al periodo stagionale in cui veniva a mancare il suo apporto. 
pecudum numero non est, veluti canem aut feram bestiam, vulneraverit aut occiderit, hoc capite actio constituitur. in ceteris quoque omnibus animalibus, item in omnibus rebus quae anima carent damnum iniuria datum hac parte vindicatur. si quid enim ustum aut ruptum aut fractum fuerit, actio ex hoc capite constituitur: quamquam poterit sola rupti appellatio in omnes istas causas sufficere: ruptum enim intellegitur, quod quoquo modo corruptum est. unde non solum usta aut fracta, sed etiam scissa et collisa et effusa et quoque modo perempta atque deteriora facta hoc verbo continentur: denique responsum est, si quis in alienum vinum aut oleum id immiserit, quo naturalis bonitas vini vel olei corrumperetur, ex hac parte legis eum teneri. Illud palam est, sicut ex primo capite ita demum quisque tenetur, si dolo aut culpa eius homo aut quadrupes occisus occisave fuerit, ita ex hoc capite ex dolo aut culpa de cetero damno quemque teneri. hoc tamen capite non quanti in eo anno, sed quanti in diebus triginta proximis res fuerit, <obligatur $>$ is qui damnum dederit. Ac ne plurimi quidem verbum adicitur. sed Sabino <recte> placuit perinde habendam aestimationem, ac si etiam hac parte plurimi verbum adiectum fuisset: nam plebem Romanam, quae Aquilio tribuno rogante hanc legem tulit, contentam fuisse, quod prima parte eo verbo usa est

- Ulp. 18 ad ed. D. 9, 2, 27, 5: Tertio autem capite ait eadem lex Aquilia: Ceterarum rerum praeter hominem et pecudem occisos si quis alteri damnum faxit, quod usserit fregerit ruperit iniuria, quanti ea res erit in diebus triginta proximis, tantum aes domino dare damnas esto 46

- Gai 3, 217, così come ricostruito nei F.I.R.A. e nelle altre moderne edizioni, individua come oggetto del terzo caput ogni altro danno: sia il ferimento di schiavi e pecudes, sia il ferimento e l'uccisione dei quadrupedi che non sono pecudes, comprese le ferae bestiae, sia qualsiasi damnum iniuria datum in ceteris omnibus animalibus nonché in omnibus rebus quae anima carent attuato con le condotte di urere frangere rumpere. Il testo è stato, però, integrato in base alle Istituzioni di Giustiniano; può essere per noi di interesse esaminarlo anche così come appare nella trascrizione di Goeschen del codice veronese ${ }^{47}$ :

8) Capite tertio de omni cetero damno cavet itaque si

9) quis serū $\bar{u}$ eam qdrupedem que pecudem nu

10) mero de ūu canem à feram vestiam $\bar{u}$ ursum leo

11) nem uulneraverit $\bar{u}$ occiderit ex hoc capite ao.

12) constituit in ceteris qq animalib item in omni

13) b rebus qua anima carent damnum iniuria dat

\footnotetext{
46 Sia damnas sia aes sono stati ritenuti segni dell'antichità della lex Aquilia: la formula damnas esto (su cui si veda D. LIEBS, Damnum, Damnare und damnas. Zur Bedeutungsgeschichte einiger lateinischer Rechtswoerter, in «ZSS» 85 (1968) 249 ss.), ricorre in N.A. 6, 3, 36-37, in cui Gellio riferisce le parole di Catone nell'orazione pro Rhodiensibus del 167 a.C.: Verba autem ex ea oratione M. Catonis haec sunt: .... Deinde paulo infra dicit: Quid nunc? ecqua tandem lex est tam acerba, quae dicat "si quis illud facere voluerit, mille minus dimidium familiae multa esto; si quis plus quingenta iugera habere voluerit, tanta poena esto; si quis maiorem pecuum numerum habere voluerit, tantum damnas esto? Troviamo damnas anche in Plauto Truc. 893: Ego minam auri fero supplicium damnas ad amicam meam (ma secondo altra versione damnis). Il termine aes, che non si trova più nel linguaggio legislativo a partire dalla metà del II sec.a.C., è utilizzato da Plauto, ad esempio, in Asin. 201, Aul. 376, 520, 526, 528, Cas. 23, Most. 63, Poen. 24, Stich. 203.

${ }^{47}$ Riprendo il testo di recente pubblicato da F. BRIGuglio, La prima trascrizione delle Istituzioni di Gaio. Il Codex DCCCIX (DCCCXIII) Gaii Institutionum Libri della Biblioteca Capitolare di Verona, Bologna 2013, 134.
} 


\section{4) hac parte vindicat}

Dopo l'affermazione per cui capite tertio de omni cetero damno cavet, si parla dello schiavo e del quadrupede del numero dei pecudes, poi del cane o della fera bestia come l'orso e il leone, e solo in seguito degli altri animali e delle res quae anima carent. Nel dettato che ci è pervenuto manca, però, sicuramente qualcosa perché si parla di vulnerare e occidere anche riguardo a schiavi e pecudes, la cui uccisione era già contemplata nel primo caput, e dunque l'occiderit sarebbe dovuto essere riferito solo a cani e bestie feroci e non anche agli schiavi e quadrupedi che rientrano nel numero dei pecudes. Il problema è risolto dai moderni editori con l'inserimento della parte che appare nelle Istituzioni di Giustiniano, che potrebbe essere giustificato dalla circostanza che, se nel testo era presente il termine numero per due volte, il copiatore, per una distrazione, potrebbe aver saltato ciò che veniva dopo il primo numero e ripreso dopo il secondo. Sia accettando la lettura del codice veronese, sia la versione integrata dalle Istituzioni di Giustiniano, Gaio parlerebbe, comunque, di ogni ceterum damnum. Il Cannata, che, pur riportando in nota il testo dell'apografo dello Studemund ${ }^{48}$, prende in considerazione solo il testo di Gaio integrato dalle Istituzioni di Giustiniano, ritiene che l'ambito di applicazione della lex di cui parla Gaio, relativo ad ogni ceterum damnum, non sia, però, quello originario, bensì il prodotto della successiva interpretatio, e che il terzo caput fosse in origine concepito per sanzionare solo la distruzione delle cose non previste nei capi precedenti, le ceterae res di cui parla Ulpiano in D. 9, 2, 27, 5. Mentre parte della dottrina più risalente aveva, come è noto, ritenuto una successiva inserzione ulpianea l'intera frase ceterarum rerum praeter hominem et pecudem occisos, per cui il terzo caput reciterebbe si quis alteri damnum faxit, quod usserit fregerit ruperit iniuria, prendendo cioè in considerazione qualsiasi danno arrecato iniuria con le condotte di urere frangere rumpere, il Cannata ritiene, invece, che vada espunto praeter hominem et pecudem occisos e mantenuto ceterarum rerum, da intendere in origine come 'altre cose' e non 'in altri casi'. Secondo l'autore ${ }^{49}$, inserendo il chiarimento interpretativo praeter hominem et pecudem occisos nell'antica regola generale, Ulpiano avrebbe cambiato il senso dell'intera frase: "le ceterae res non sono più le altre rispetto a schiavi e pecudes, perché la norma del primo capo, che ad essi si riferisce in modo speciale, non concerne che una serie limitata di casi, e cioè quelli della loro uccisione, ogni altro caso rientra nel terzo capo". Sarebbe, dunque, Ulpiano ad aver equivocato sul significato di ceterae res aggiungendo praeter hominem et pecudem occisos, ma sembra difficile che il giurista abbia potuto equivocare se, come afferma lo stesso Cannata ${ }^{50}$, aveva a disposizione un testo completo della legge conforme all'originale. Da nessuno dei testi che ci sono pervenuti, si ricava, pertanto, in modo chiaro che il terzo caput fosse in origine concepito per sanzionare solo la distruzione delle cose non previste nei capi precedenti ${ }^{51}$; tale circostanza sarebbe, però, ad avviso del Cannata, obbligata, dal momento che la pena consisterebbe sempre, come nel primo caput, nel pagamento del valore integrale della $\operatorname{cosa}^{52}$, e dunque sarebbe sempre stato previsto, in origine, che la res risultasse

${ }^{48}$ CANNATA, Il terzo capo, cit., 240 nt. 8: pecudum numero de ūū canem ā feram vestiam ū ursum leonem vulneraverit $\bar{u}$ occiderit.

49 CANnATA, Il terzo capo, cit., $256 \mathrm{~s}$.

${ }^{50}$ CANNATA, Sul testo originale, cit., 8 .

${ }^{51} \mathrm{Si}$ veda, in tal senso, per la dottrina risalente, N. NATALI, La legge Aquilia, Roma 1896, rist. Roma 1970, 27 s.: 'In questo capitolo si reprimeva il danno materiale diverso dalla uccisione di un servo o quadrupes pecus e dalla acceptilatio in fraudem creditoris; rientra perciò nel $3^{\circ}$ capitolo della legge qualunque danno arrecato con incendio (usserit), mediante frattura (fregerit), ed in qualsiasi altro modo, e perciò anche la uccisione di un animale che non appartenga alla categoria dei quadrupedi pecudi e il ferimento dello schiavo e di qualunque animale'; per la dottrina recente BignARDI, Theoph. Par. 4.3.15, cit., 26 e ivi nt. 44, VALDiTARA, Damnum², cit., 14 ss.

${ }^{52} \mathrm{La}$ circostanza che si dovesse pagare il valore della res in diebus triginta proximis mostrerebbe, inoltre, che, pur potendo l'impiego del verbo rumpere alludere a fatti che non producevano la distruzione della cosa, ma la sua inutilizzabilità, sarebbe stato sempre previsto, in origine, che la res risultasse perduta. 
perduta; la condanna in quanti in diebus $X X X$ proximis ea res fuerit ${ }^{53}$ non potrebbe che riguardare casi di distruzione. L'Autore, pur ammettendo che costituirebbe una stranezza, una vistosa lacuna, che la lex Aquilia non prendesse in alcun modo in considerazione i danneggiamenti a schiavi e pecudes ma solo nel primo caput la loro uccisione ${ }^{54}$, ritiene che questo possa essere spiegato perché tali danneggiamenti sarebbero stati già sanzionati nelle XII Tavole o magari in leggi successive ${ }^{55}$. Se anche non conosciamo tutte le norme delle XII Tavole in materia di danno, quel che sappiamo è, per l'autore, sufficiente per stabilire che esse prevedevano non solo l'os fractum dello schiavo ma tutta una serie di 'danneggiamenti non distruttivi', per i quali la pena era espressa con la locuzione noxiam sarcire, come il nocumento arrecato da rivus aquae ductus ${ }^{56}$, da pauperies ${ }^{57}$ e incendio involontario ${ }^{58}$, danneggiamenti che non appaiono, a mio avviso, sempre non distruttivi. L'esistenza di una sanzione pre-aquiliana nelle XII Tavole o magari in una legge successiva sarebbe confermata, per il Cannata, da

- Liv. 22, 10, 3-5: tum donum duit populus Romanus Quiritium quod ver attulerit ex suillo ovillo caprino bovillo grege quaeque profana erunt Iovi fieri, ex qua die senatus populusque iusserit. Qui faciet, quando volet quaque lege volet facito; quo modo faxit probe factum esto. Si id moritur quod fieri oportebit, profanum esto, neque scelus esto. Si quis rumpet occidetve insciens, ne fraus esto

Si parla della lex de vere sacro vovendo del 217 a.C., che trattava non solo della occisio ma anche della ruptio di pecudes oggetto di sacrificio, escludendo, nel caso l'autore fosse insciens, lo scelus. L'utilizzo del decemvirale ne fraus esto e non di iniuria proverebbe, per il Cannata, che la lex Aquilia non esisteva ancora ${ }^{59}$; per il Valditara le osservazioni del Cannata circa l'assenza di un riferimento all'inuria e l'utilizzo del decemvirale ne fraus esto appaiono, peraltro, inconferenti, in quanto ciò che rilevava non era la liceità giuridica (iure) del comportamento dannoso, quanto la non consapevolezza (insciens). Per il Corbino ${ }^{60}$, inoltre, il fatto che nella rogatio si prendano in considerazione una ruptio e una occisio come possibili fatti di perdita incolpevole di animali consacrati, "può considerarsi, con buona probabilità, circostanza che echeggia il linguaggio legislativo", ma non si può dire se nel senso che lo presupponga o che lo anticipi; solo nel primo caso la circostanza diverrebbe elemento di datazione significativo.

${ }^{53}$ Per G. VALDITARA, Dall'aestimatio rei all'id quod interest nell'applicazione della condemnatio aquiliana, in L.VACCA (a cura di), La responsabilità civile da atto illecito nella prospettiva storico-comparatistica, Torino 1995, 76 ss., è riconosciuto pressochè unanimemente che il punto di partenza è costituito dalla stima della cosa distrutta o danneggiata, in una pura aestimatio rei (v. anche G. VALDITARA, Superamento dell'aestimatio rei nella valutazione del danno aquiliano ed estensione della tutela ai non domini, Milano 1992, 4 s., 278 ss.).

${ }^{54}$ CANNATA, Il terzo capo, cit., 131 nt. 89, 132 nt. 96.

55 Per l'autore (258) il legislatore, che possiamo identificare con il tribuno Aquilio, scelse di sanzionare solo i danneggiamenti che eliminavano la cosa, intendendo che per i deterioramenti restassero in vigore le norme precedenti: egli non avrebbe, in altri termini, pensato di emanare una legge che, come si esprimerà poi Ulpiano, regolava interamente la materia dei danneggiamenti di cose altrui abrogando l'insieme delle norme precedenti in materia 'appartenessero esse alle XII Tavole o a qualunque altra legge', ma avrebbe inteso riformare il sistema delle pene sostituendone a quello arcaico uno più moderno ed economicamente fondato (vedi G. CARDASCIA, La portée primitive de la loi Aquilia, in Daube noster, Edimburgh 1974, 60 ss., in part. 63 s.).

${ }^{56}$ tab. VII.8b. Paulus D. 43, 8, 5: Si per publicum locum rivus aquae ductus privato nocebit, erit actio privato ex lege XII tab., ut noxae domino caveatur.

${ }^{57}$ tab. VIII.6 Ulpianus (1. XVIII ad ed.) D. 9, 1, 1 pr.: Si quadrupes pauperiem fecisse dicetur, actio ex lege XII tab. descendit; quae lex voluit aut dari id quod nocuit - aut aestimationem noxiae offerri.

${ }^{58}$ tab. VIII.10 Gaius (1. 4 ad 1. XII tab.) D. 47, 9, 9: Qui aedes acervumue frumenti iuxta domum positum combusserit, vinctus verberatus igni necari iubetur, si modo sciens prudensque id commiserit; si vero casu, id est neglegentia, aut noxiam sarcire iubetur, aut, si minus idoneus sit, levius castigator.

${ }^{59}$ Se si accoglie la datazione della lex Aquilia proposta dal Cannata, la distanza fra le due leggi sarebbe, peraltro, di pochi anni.

${ }^{60}$ Corbino, Il danno qualificato ${ }^{2}$, cit., $59 \mathrm{~s}$. 
Per il Valditara ${ }^{61}$, il testo di Livio smentisce, in ogni caso, la tesi dell'originaria estraneità al contesto aquiliano delle ipotesi di ruptio di servi e pecudes ${ }^{62}$ : la connessione fra rumpere e occidere è un argomento troppo forte per non pensare che si presupponessero proprio le due ipotesi dei due capi della lex Aquilia; al di là della datazione della legge, da Livio si ricaverebbe indubitabilmente che occisio e ruptio di pecudes erano considerate due ipotesi distinte ma parallele: sarebbe stato impensabile che la lex Aquilia ne trattasse una soltanto, anche ammesso che fosse successiva al 217 a.C. Ma per il Cannata ${ }^{63}$, considerando il terzo caput applicabile fin dall'inizio anche a danneggiamenti non distruttivi di schiavi e pecudes, si sarebbe di fronte ad una stranezza 'ben più massiccia' rispetto a quella costituita dall'assenza di previsioni per il danneggiamento di schiavi e animali: se nel terzo caput fosse stata stabilita un'unica sanzione "consistente nel sorgere, in capo al colpevole, dell'obbligazione di pagare al proprietario il valore della cosa danneggiata", sarebbe assurdo che chi avesse solo danneggiato il bene, ad esempio tagliato la coda ad un cane, dovesse dare al proprietario la stessa somma che se l'avesse ucciso ${ }^{64}$. A prescindere dalla considerazione che tagliare la coda al cane non sembra costituire un rumpere, in quanto nessun danno viene arrecato, se condannare al quanti ea res avesse significato condannare al valore integrale della cosa, nel caso prospettato da Bruto si sarebbe dovuto pagare il valore integrale della schiava o della cavalla. Il problema è sempre stato avvertito dalla dottrina: già il Pernice ${ }^{65}$ aveva ritenuto che sin dall'inizio l'espressione quanti ea res fosse interpretata nel senso che si doveva consegnare la cosa danneggiata, altrimenti ferimento e uccisione si sarebbero posti sullo stesso piano comminandosi la stessa pena per l'uno e per l'altro; per il Natali ${ }^{66}$ doveva detrarsi dal maggior valore raggiunto dall'oggetto nel mese precedente il valore più basso dell'oggetto dopo il delitto, quando il danneggiato non avesse preferito consegnare l'oggetto leso. Dal momento che il valore di una cavalla o una schiava praegnas è indubbiamente maggiore per via dell'aspettativa che la gravidanza vada a buon fine, la perdita in seguito ad un comportamento altrui del feto potrebbe, peraltro, portare, come osservava il Pugliese ${ }^{67}$, alla condanna del convenuto al pagamento di una somma pari

61 VALDITARA, In tema, cit., 202.

${ }^{62}$ In tal senso già Von LuBTOW, Untersuchungen, cit., 109 ss., il quale ritiene che il terzo capo, strettamente connesso al primo, non ripetesse però la menzione letterale di servus serva quadrupes pecus, cui esclusivamente si riferiva; l'estensione agli altri beni sarebbe stato reso possibile proprio dal tenore generale: si quis alteri damnum faxit.

${ }^{63}$ CAnnAtA, Sul testo, cit., 25 ss., in part. 47 ss.; ID., Il terzo capo, cit., 247 ss. L'autore nel primo articolo osservava che Bruto, nel considerare oggetto della ruptio la cavalla, si poneva 'già del tutto nella linea della giurisprudenza successiva, che interpretava la locuzione ceterae res del terzo capo come altri casi'. Replica però BIGNARDI, Frangere e rumpere, cit., 43 ss., che non si può ammettere che Bruto avesse esteso l'applicazione del terzo caput all'ipotesi delle lesioni a schiavi e pecudes senza con ciò ammettere che tale ampliamento implicava anche, se non prima, la comprensione nel rumpere di lesioni che non determinavano la distruzione della cosa. Pertanto, accettando la rituale lettura di D. 9, 2, 27, 22, e la consequenziale interpretazione del successivo responso di Quinto Mucio, si dovrebbe affermare che, in sede di interpretazione estensiva della legge, i due giuristi di età repubblicana avrebbero operato in modo da far rientrare nella previsione del terzo capo le lesioni a schiavi e pecudes, senza però estendere lo stesso principio, e cioè responsabilità per il danneggiamento che non comportasse distruzione del bene, anche alle ceterae res.

${ }^{64}$ F. SCHUlz, Classical Roman Law, Oxford 1951, 590, ritiene non debba destare sorpresa, tenendo a mente la natura penale dell'azione, che anche se una res avesse solo subito un deterioramento e non fosse completamente distrutta, l'offensore dovesse pagare il pieno valore del bene. La pena era la stessa quando un cane (che non rientrava tra $\mathrm{i}$ pecudes) era ucciso e quando era solo ferito, ed è 'primitivo' non distinguere fra i due casi, ma le vecchie leggi mostrerebbero caratteristiche 'primitive'. Per D. PUGSLEY, On the Lex Aquilia and Culpa, in «TRD» 50 (1982) 1 ss.= American are Aliens and Other Essays on Roman Law, Exeter 1989, 58, Gaio dà decisamente l'impressione che la misura dei danni fosse il pieno valore dello schiavo, il suo più alto valore nei passati trenta giorni. Poichè il diritto non era così 'primitivo', e certamente non lo era quello classico, bisogna vedere, per l'autore, se ci sono altre possibili interpretazioni.

${ }^{65}$ PERNICE, Zur Lehre, cit., 240, ritiene che, se il danneggiato non avesse preferito consegnare l'oggetto leso, dovesse detrarsi dal maggior valore raggiunto dall'oggetto nel mese precedente il valore più basso dell'oggetto dopo il delitto.

${ }^{66}$ NATALI, La Legge Aquilia, cit., 162 ss.

${ }^{67}$ Pugliese, Il diritto e la vita materiale, in Atti dei convegni lincei, 61, Roma 1984. 
alla differenza tra il valore che la cavalla incinta avesse avuto nell'ultimo mese anteriore al delitto e il suo valore dopo ''aborto $^{68}$. Per il Cannata ${ }^{69}$, la valutazione doveva essere effettuata non come pretium corporis, ma come quantificazione pecuniaria del danno subito dal proprietario a causa della ruptio: il valore del fetus ruptus corrisponderebbe alla diminuzione di valore venale, che l'aborto ha cagionato, della cavalla gravida ${ }^{70}$. Anche per il Cannata, dunque, Bruto avrebbe calcolato il valore da risarcire tenendo conto della perdita economica subita dal proprietario e non del valore integrale della res.

Da ultimo, il Valditara ${ }^{71}$ ritiene invece che si dovesse risarcire il maggior valore del bene negli ultimi trenta giorni, tenendo conto della circostanza che l'actio legis Aquiliae era un'azione penale: nell'ambito della clausola quanti ea res fuit/ fuerit non era possibile una stima del fetus, ma la perdita del partus come bene futuro rappresentava certamente un pregiudizio economico (damnum) per il proprietario della cosa madre: "Il riconoscimento che la schiava ovvero la cavalla gravida erano state fisicamente danneggiate, esemplarmente evidente in Quinto Mucio, ma chiaramente presupposto anche da Bruto, fa ritenere che l'aestimatio avesse ad oggetto l'unico bene giuridicamente esistente, ovverosia il corpus della serva o della cavalla". "Nell'ambito di una aestimatio rei", prosegue l'autore, "il valore di mercato di una madre gravida sarebbe stato senz'altro più elevato di quello di una schiava/giumenta comune. Era questo pertanto l'oggetto della condanna a cui sia Bruto sia Quinto Mucio dovevano tendere: il maggior valore di una schiava/cavalla gravida". Il Valditara ritiene, pertanto, che anche per il terzo caput si dovesse risarcire il maggior valore del bene; la differenza con il primo caput consisterebbe solo nel maggior arco temporale del primo (l'anno) rispetto al terzo (trenta giorni). Ai tempi di Bruto e Quinto Mucio il damnum non sarebbe stato valutato come perdita economica ma come violazione dell'integrità fisica di un bene ${ }^{72}$, in quanto quest'ultimo sarebbe il significato più risalente. Mi pare, peraltro, che il termine damnum col significato di perdita economica, spesso contrapposto a lucrum nel senso di guadagno, sia già attestato in una serie di passi di Plauto. Si vedano ad esempio

- Asin. 181 ss.: Is dare volt, is se aliquid posci, nam ibi de pleno promitur; neque ille scit quid det, quid damni faciat, 187: perdidici istaec esse vera damno cum magmo meo

- Capt. 324 ss.: Ego virtute deum et maiorum nostrum dives sum satis. Non ego omnino lucrum omne esse utile homini existumo: scio ego, multos iam lucrum lutulentos homines reddidit. Est etiam ubi profecto damnum praestet facere quam lucrum

- Cist. 106: Quamquam mi istud erit molestum triduum, et damnum dabis, faciam

\footnotetext{
${ }^{68}$ La circostanza che il valore del parto possa essere stimato risulta, anche se si tratta di un giurista più tardo, da Tryph. 4 disp. D. 49, 15, 12, 18: Si natum ex Pamphila legatum tibi fuerit tuque matrem redemeris et ea apud te pepererit, non videri te partum ex causa lucrativa habere, sed officio arbitrioque iudicis aestimandum constituto pretio partus, perinde atque si, quanto mater est empta, simul et partus venisset. Nel riscatto della madre il redemptor ha pagato un prezzo più alto perché la donna era praegnas e dunque la summa redemptionis comprende anche il prezzo del nascituro; dovrà pertanto essere stimato il prezzo del parto. Per un esame più approfondito del passo mi permetto di rimandare a M.V. SANNA, Nuove ricerche in tema di redemptio ab hostibus, Cagliari 2001; EAD., Conceptus pro iam nato habetur e nozione di frutto, in F. BotTA (a cura di), Il diritto giustinianeo fra tradizione classica e innovazione, Torino 2003, 217 ss.

${ }^{69}$ Cannata, Sul testo della lex Aquilia, cit., 175.

${ }^{70}$ Concorda col Cannata GALEOTTI, Ricerche, I, cit., 249 (su cui vedi di recente, M.F. CuRSI, in «Iura» 64 (2016) 458 ss. cit., 85 ss., e F.B.F. RodRIGUES ROCHA, in «Interpretatio prudentium», I (2016) 2, 285 ss.), per la quale la somma da corrispondere al dominus dovrà essere calcolata misurando l'incidenza che la perdita del feto ha avuto sul valore della schiava o della pecus, e dunque il pretium corporis del fetus ruptum corrisponderà alla diminuzione del valore venale della madre, cagionato dall'aborto.

71 VALDITARA, In tema, cit., 197 ss.

72 VALDITARA, Sulle origini del concetto di damnum², Torino 1998; ID., In tema, cit., 197 ss.
} 
- Men. 256 ss.: Ne tu hercle, opinor, nisi domum revorteris, ubi nihil habebis, geminum dum quaeris, gemes. Nam ita est haec hominum natio: in Epidamnieis voluptarii atque potatores maxumei; tum sycophantae et palpatores plurumei in urbe hac habitant; tum meretrices mulieres nusquam perhibentur blandiores gentium. Propterea huic urbei nomen Epidamno inditumst, quia nemo ferme huc sine damno devortitur, 268: Ne mihi damnum in Epidamno duis

- Merc. 236: ait sese illius opera atque adventu caprae flagitium et damnum fecisse hau mediocriter; dicit capram, quam dederam servandam sibi, suai uxoris dotem ambedisse oppido

- Poen. 327 ss.: Ecquid amare videor? Damnum, quod Mercurius mimime amat. Namque edepol lucrum amare nullum amatorem addecet, 748 ss.: qui in re divina dudum dicebant mihi malum damnumque maxumum portendier: is explicavi meam rem postilla lucro

- Trinum. 1022 ss.: inter eosne homines condalium te redipisci postulas? Quorum eorum unus surrupuit currenti cursori solum. Ita me di ament, graphicum furem. Quid ego quod periit petam? Nisi etiam laborem ad damnum adponam epithecam insuper. Quin tu quod periit periisse ducis?

Il termine damnum dunque già per Plauto può significare perdita economica; se pensiamo con il Cannata ad una datazione della lex Aquilia nel 210/200, ma anche in un periodo precedente, non si tratterebbe di un significato tardo, ma con tutta probabilità del significato originario $^{73}$.

3. D'altra parte, così come ceterarum rerum non significa necessariamente 'delle altre cose', ma può significare anche 'degli altri casi, degli altri affari', ea res nel terzo caput può significare 'that matter', e cioè, con il Crawford "a generic reference to the pecuniary loss; and the pecuniary loss in turns depends on the value of the king involved and what has been done to it". Osserva, inoltre, l'autore che "it is thus not certain that the 30 days follow, rather than precede, the act damnum faxit" $"$. Occorre, infatti, tener conto del fatto che nel passo di Ulpiano si afferma quanti ea res erit in diebus triginta proximis, con il verbo al futuro; il Daube ${ }^{75}$, con una tesi che ebbe un certo seguito in dottrina in passato ${ }^{76}$, ma che sembra oggi nuovamente condivisa da una parte della dottrina ${ }^{77}$, aveva ritenuto che il terzo caput della lex Aquilia con quanti ea res erit in diebus triginta proximis non intendesse riferirsi al valore del bene nei

73 J.M. KeLLY, The Meaning of the Lex Aquilia, in «LQR» 80 (1964) 73 ss., pone in evidenza che Plauto, nato certamente non molto dopo 30 anni la lex (286 a.C.), utilizza damnum come 'pecuniary loss or expense', opponendolo frequentementemente a lucrum come profitto.

${ }^{74}$ M.H. Crawford, Roman Statutes, II, London 1996, 726. Anche per Von LubTow, Untersuchungen, cit., 25, damnum indica non il 'Beschädigung', ma la perdita patrimoniale, il pregiudizio economico ('Vermögensverlust').

75 DAube, On the Third Chapter, cit., 3 ss.

${ }^{76} \mathrm{Si}$ vedano J.A. ILIFFE, Thirty Days hath Lex Aquilia, in «RIDA» 5 (1958) 493 ss.; KeLLY, The Meaning, cit., 73 ss.; ID., Further Reflections on the Lex Aquilia, in Studi Volterra I, Milano 1971, 235 ss. Sembra dello stesso parere relativamente all'originaria previsione della lex Aquilia anche A. WATsON, Personal Injures in the XII Tables, in «TR» 43 (1975) 213 ss., per il quale il significato di ruperit sarebbe stato esteso, in un secondo momento, sino al danneggiamento di cose inanimate

77 CoRbinO, Il danno qualificato ${ }^{2}$, cit., 181 ss.; M. BRUTTI, Il diritto privato nell'antica Roma ${ }^{3}$, Torino 2015 , 534 ss. V. anche R. ZimMERmanN, The Law of Obligations, Cape Town-Johannesburg 1990, 968 s., per il quale 'the period of 30 days may well have been taken over from XII Tables; for in the olden days the condemned debtor had been granted exactly this period of time to pay or render restitution and thus to avert the harsh consequences of manus iniectio. This kind of regime made perfect sense under the lex Aquilia too; before the judge could be asked to asses the damages, a period of 30 days had to elapse; within this time-span a wound might have healed, the debtor might have paid a sum that satisfied the other party, he might have repaired the sedan chair that he had damaged or he might have given his creditor a new one' 
trenta giorni passati, ma al danno, cioè alla perdita economica sofferta dal proprietario, nei trenta giorni seguenti ${ }^{78}$. Lo stesso Ulpiano usa però il fuit in

- 18 ad ed. D. 9, 2, 29, 8: Haec verba: quanti in triginta diebus proximis fuit, etsi non habent plurimi, sic tamen esse accipienda constat

e Gaio il fuerit in

- Gai 3, 218: Hoc tamen capite non quanti in eo anno, sed quanti in diebus XXX proximis ea res fuerit, damnatur is qui damnum dederit

La tesi del Daube sembrava ormai abbandonata dalla dottrina prevalente, convinta, in particolare dopo le osservazioni dell'Ankum ${ }^{79}$, che la lex Aquilia usasse il verbo al passato e che l'erit di D. 9, 2, 27, 5 fosse dovuto ad un errore del copista; anche il Cannata ${ }^{80}$ ritiene si tratti di un errore, pur osservando che non si può parlare, con l'Ankum, di un 'fantasme florentin', perché l'erit compare nei manoscritti della Vulgata, e dunque l'errore della Littera Florentina poteva essere condiviso da altri manoscritti. E' impensabile, però, osserva l'autore, che sia Gaio sia Ulpiano, che operavano un confronto del terzo capo col primo per notare l'assenza nel terzo del termine plurimi, passassero sotto silenzio la differenza fra l'erit nel terzo e il fuit nel

${ }^{78}$ Per il Daube il terzo caput avrebbe, inoltre, preso in origine in considerazione solo il ferimento di schiavi e animali, res semoventes, mentre in seguito sarebbe stato esteso agli oggetti inanimati; solo in tal momento i dies triginta proximi sarebbero stati intesi come gli ultimi 30 giorni e quindi sarebbero sorte le difficoltà per quanto riguarda la parola mancante plurimi, che in origine non avrebbe avuto ragione d'essere, in quanto, essendo l'intervallo dei trenta giorni successivi stabilito per consentire al giudice di constatare l'evoluzione della lesione, il valore massimo o minimo avrebbe avuto un'importanza relativa. Se solo Sabino, come sembra risultare da Gai 3, 218, avrebbe dato 'i tocchi finali' alla dottrina che applica il terzo caput a qualunque danno, dal momento che Labeone concede l'azione in caso di danneggiamento di un oggetto inanimato (Ulp. 18 ad ed. D. 9, 2, 29, 3: Item Labeo scribit, si, cum vi ventorum navis impulsa esset in funes anchorarum alterius et nautae funes praecidissent, si nullo alio modo nisi praecisis funibus explicare se potuit, nullam actionem dandam. idemque Labeo et Proculus et circa retia piscatorum, in quae navis piscatorum inciderat, aestimarunt. plane si culpa nautarum id factum esset, lege Aquilia agendum. sed ubi damni iniuria agitur ob retia, non piscium, qui ideo capti non sunt, fieri aestimationem, cum incertum fuerit, an caperentur) si può ritenere, per l'autore, che il decisivo cambiamento nello scopo del terzo caput abbia preso piede nella seconda metà del I sec. a.C. Se, invece, si ritenesse che sin dall'inizio il terzo caput si riferisse al valore dell'ultimo mese precedente, questo avrebbe comportato instabilità nel modo del calcolo per alcune centinaia di anni, il che è per il Daube massimamente improbabile. Inoltre, se si parlasse del più alto valore della cosa danneggiata, anche il $3^{\circ}$ caput, come il primo, sarebbe applicabile solo a casi di distruzione completa, mentre sappiamo che fu applicato anche a casi di distruzione parziale. Il sistema delle XII Tavole relativo al membrum ruptum e all'os fractum doveva aver portato frequentemente, per il Daube, a risultati ingiusti, in quanto il valore del denaro e dei beni fluttuava, perciò la lex Aquilia avrebbe fatto in modo che, a prescindere dal tipo di ferita, ogni danno reale dovesse essere risarcito, ma non tutte le conseguenze delle ferite erano subito manifeste, in quanto lo schiavo ferito poteva guarire completamente o rimanere invalido, il costo delle cure poteva essere alto o basso. Quando la lex Aquilia introdusse la stima individuale di ogni danno, contro la pena fissa delle XII Tavole, necessariamente intendeva prendere in considerazione, per l'autore, non l'esatto momento del ferimento ma il risultato finale, che non poteva essere posticipato troppo a lungo, ma doveva essere limitato a non più di 30 giorni. Per D. PUGSLEY, The Origins of the Lex Aquilia, in «LQR» 85 (1969) 50 ss., "chapter 3 of the lex aquilia was passed to provide a flexibile measure of damages for personal injuries in place of the delle fixed penalties of the XII Tables. So that if you run down me or my slave damages will be at large, instead of being confinated to 300 and 150 asses respectively", deterrente insufficiente, in quanto, trattandosi di una pena fissa non distingueva fra un milionario e un povero, tra conseguenze più o meno gravi. Per l'autore l'inserimento di plurimi sarebbe espressione di uno sconvolgimento del carattere originario del plebiscito, e risultato dell'influenza negativa del I capitolo. Mentre il primo caput sarebbe nato per i casi nei quali non vi fosse possibilità di esperire l'azione di rivendica, e avrebbe avuto alle origini natura satisfattoria, il terzo avrebbe avuto sin dall'inizio carattere penale. Solamente agli inizi del II secolo a.C. la prima parte della lex avrebbe acquisito carattere penale e, integrandosi con il terzo caput, avrebbe dato origine al delitto di danneggiamento; l'opinione di Sabino sarebbe dovuta ai problemi che sorsero quando i criteri del primo caput furono applicati anche al terzo.

79 C. H. ANKUM, Quanti ea res erit in diebus XXX proximis dans le troisième chapter de la lex Aquilia: un fantasme florentin, in Melanges Ellul, Paris 1983, 171 ss., ora in Nueva Antología Romanística, Madrid Barcelona, Buenos Aires Sao Paulo 2014, 93 ss., attribuisce l'errore dell'erit al copista della Littera Florentina.

${ }^{80}$ Cannata, Il terzo caput, cit., 124. 
primo caput. Di recente la discussione sembra, però, riaperta, in quanto, ad avviso del Corbino ${ }^{81}$, dal dettato di Gai. 7 ad ed. prov. D. 9, 2, 2 pr. (quanti id in eo anno plurimi fuit) e Ulp. 18 ad ed. D. 9, 2, 27, 5 (quanti ea res erit in diebus triginta proximis) risulta che, mentre il primo capitolo considerava unicamente la distruzione della cosa, il terzo disciplinava qualunque fatto potesse diminuirne il valore economico ${ }^{82}$. Mentre dunque il damnum era per il primo capitolo coincidente con il valore del bene, poteva per il terzo coincidervi se la cosa fosse risultata distrutta, ma anche non coincidere quando fosse solo diminuita nel valore economico, come nel caso di ferimento o mutilazione dello schiavo o dell'animale. L'idea che la sanzione inglobasse l'intero valore della cosa non può per il Corbino essere accolta, come dimostrato da Ulp. 50 ad Sab. D. 9, 2, 46: Si vulnerato servo lege Aquilia actum sit, postea mortuo ex eo vulnere agi lege Aquilia nihilo minus potest e Iul. 86 dig. D. 9, 2, 47: Sed si priore iudicio aestimatione facta, postea mortuo servo, de occiso agere dominus instituerit, exceptione doli mali opposita compelletur, ut ex utroque iudicio nihil amplius consequatur, quam consequi deberet, si initio de occiso homine egisset. Pensare che la valutazione ex capite tertio si sia circoscritta alla intervenuta concreta diminuzione di valore della cosa solo per effetto di un atteggiamento interpretativo successivo, come ritiene il Cannata, è escluso, per il Corbino, dal dettato normativo dei due capi, che differisce non solo per l'id e l'ea res, ma anche per l'uso dei due diversi tempi verbali nell'indicazione di ciò che dovrà essere valutato: nel primo caput qualcosa di non più esistente, sicchè la determinazione del valore monetario non potrà che essere riferita al passato (fuit), nel terzo qualcosa che può invece essere ancora esistente. Anche per il Brutti ${ }^{83}$ l'idea del Cannata che ai sensi del terzo caput - a suo avviso relativo a qualunque fatto potesse diminuire il valore economico della res - il danneggiato ottenesse una sanzione che inglobava il valore della cosa è smentita dal fatto che se si era agito tertio capite per il ferimento di uno schiavo e poi questo moriva, si poteva agire per il primo capo, come prova D. 9, 2, 46: l'avere agito de vulnerato non impediva una successiva azione de mortuo. Mentre nel primo caput il valore della condanna equivale necessariamente alla cosa nella sua interezza - ed è credibile che la cosa perduta fosse valutata con riferimento all'ultimo anno precedente il fatto - per quanto riguarda il terzo caput, se l'ammontare della condanna deve corrispondere alla perdita di valore per il deterioramento causato dal reo, allora sarà necessario valutare in concreto gli effetti lesivi del comportamento dannoso, dopo che si sono verificati; anche il congiuntivo perfetto fuerit di Gaio potrebbe, d'altra parte, ben indicare una valutazione circa il danno che si sviluppa dopo l'evento. Osserva, però, di recente il Valditara ${ }^{84}$ che da D. 9, 2, 47 si può solo ricavare che il valore massimo conseguibile, quando si sia agito prima ex vulnerato e poi de occiso, è quanto si sarebbe conseguito agendo subito de occiso, ammontare che poteva essere più elevato perché la stima veniva riferita all'anno e non al mese precedente. Per l'autore, come già si è detto, non vi sono motivazioni sufficienti per ritenere che il terzo caput portasse ad un oggetto della condemnatio diverso dal primo, vale a dire che non liquidasse il valore del bene, bensì il valore della lesione prodotta.

Se la tesi secondo cui per il terzo caput il danno doveva essere valutato nei trenta giorni successivi all'evento presenterebbe senza dubbio il vantaggio di consentire di tener conto dei

${ }^{81}$ CORBINO, Il danno qualificato ${ }^{2}$, cit., 181 ss.; ID., L'oggetto dell'aestimatio damni, cit., 699 ss.

82 Occorre, però, osservare che mentre in Gai. 7 ad ed. prov. D. 9, 2, 2 pr. si legge: Lege Aquilia capite primo cavetur: ut qui servum servamve alienum alienamve quadrupedem vel pecudem iniuria occiderit, quanti id in eo anno plurimi fuit, tantum aes dare domino damnas esto, non riportano id, ma ea res Gai 3, 210: Damni iniuriae actio constituitur per legem Aquiliam, cuius primo capite cautum est, 〈ut> si quis hominem alienum alienamve quadrupedem quae pecudem numero sit iniuria occiderit, quanti ea res in eo anno plurimi fuerit, tantum domino dare damnetur e I. 4, 3 pr.: Damni iniuriae actio constituitur per legem Aquiliam. cuius primo capite cautum est, ut si quis hominem alienum alienamve quadrupedem quae pecudum numero sit iniuria occiderit, quanti ea res in eo anno plurimi fuit, tantum domino dare damnetur.

${ }^{83}$ BRUTTI, Il diritto privato ${ }^{3}$, cit., 534 ss.

84 VALDITARA, In tema, cit., 197. 
danni non rilevabili al momento dell'offesa, soprattutto per quanto riguarda schiavi e animali, non si può non porre in evidenza che appare quantomeno anomalo, come già rilevato dal Cannata, che tale differenza fra il calcolo del primo caput e il calcolo del terzo non sia mai stata evidenziata dai giuristi, che pure commentano spesso, come già visto, la mancanza nel terzo caput del termine plurimi, presente nel primo. Sappiamo, in ogni caso, che non fu questa l'interpretazione di Giustiniano: negli sch. 20 e 21 ad Bas. 60, 3, 27, in cui si richiamano le Istituzioni di Giustiniano, lo scoliaste parla di giorni da computare retro:

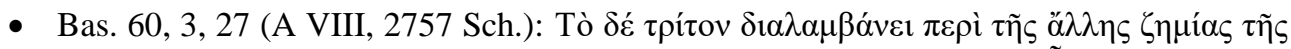

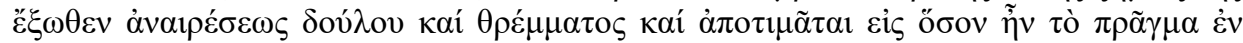

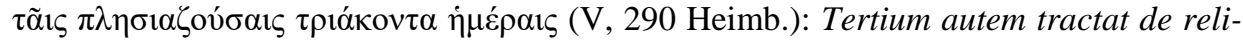
quo danno praeter occisionem servi et pecudis, et aestimatur, quanti ea res erat in proximis triginta diebus

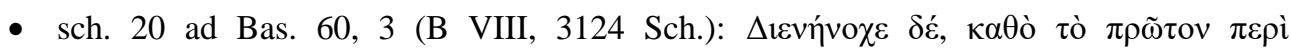

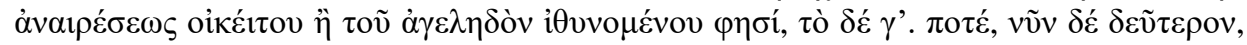

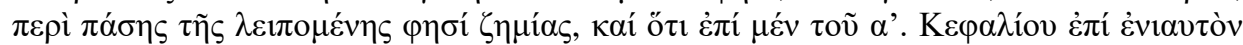

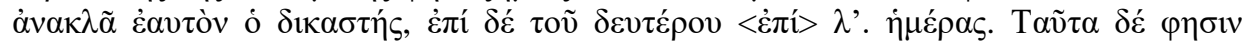

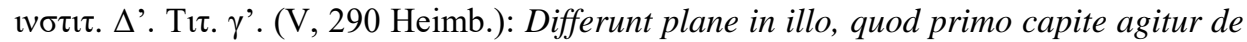
servo vel pecude occisa, tertio autem quondam, nunc vero secundo de ceteris omnibus damnis, et quod in primo capite iudex retro ad annum respicit, in secundo ad triginta dies. Haec autem traduntur Instit. 4. tit. 3.

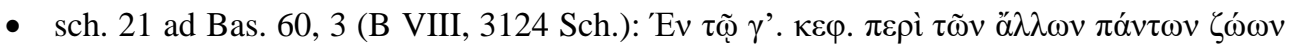

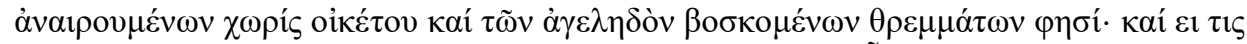

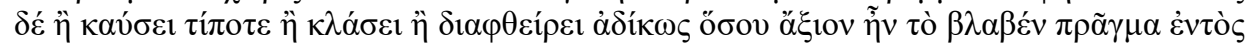

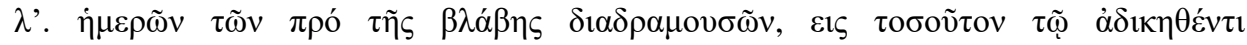
$\kappa \alpha \tau \alpha \delta 1 \kappa \alpha ́ \zeta \varepsilon \tau \alpha 1 ;(\mathrm{V}, 290$ Heimb.): in tertio capite agitur de omnibus aliis animalibus occisis praeter servum et pecudem, quae gregatim pascitur. Et si quid quis iniuria usserit, fregerit, corruperit, tanti damnatur laeso, quanti res laesa fuit in triginta diebus a damno dato retro computandis.

Se l'uso del verbo $\tilde{\eta} v$ in Bas. 60, 3, 27 non indica necessariamente il passato, la spiegazione degli scoli 20 e 21 non lascia adito a dubbi: ponendo in evidenza le differenze fra primo e terzo caput (anzi precisando che ora questo è il secondo), si parla del fatto che l'iudex per il primo retro ad annum respicit, per il terzo ad triginta dies.

Se desta, dunque, delle perplessità l'idea del Daube che il terzo caput, riguardante in origine solo schiavi e pecudes, stabilisse il pagamento della perdita economica sofferta dal proprietario nei trenta giorni seguenti al danno, perplessità mi pare nascano anche nell'accogliere l'idea che esso riguardasse, invece, solo i danneggiamenti distruttivi alle ceterae res e non a pecudes e schiavi. Né pare condivisibile l'idea del Cannata che per tali danneggiamenti sarebbero rimaste in vigore le previsioni delle XII Tavole o di norme successive; per quanto riguarda le XII Tavole, perlomeno stando alle norme che ci sono pervenute, l'unico caso previsto è, infatti, quello dell'ossis fractio dello schiavo, a meno di non voler intendere come 'norma generale di danno' quella di

- Tab. VIII. 5 “Rupit[ias] sarcito" ${ }^{85}$, lacunosa anche con l'ausilio di

- Festo 320.24: Rupitias (in) XII significat damnum dederit

${ }^{85}$ Così, nei F.I.R.A. 
- Festo 430.20: Sarcito in XII Ser. Sulpicius ait significare 'damnum solvito, praestato'.

In tal senso si è espresso di recente il Corbino ${ }^{86}$, il quale, seguendo un'idea già formulata dal Gotofredo ${ }^{87}$ e poi accolta dal Natali ${ }^{88}$, ritiene che il versetto rappresenti una 'norma generale del risarcimento del danno'; i Romani sin da Tab. VIII.5 avrebbero sempre descritto con l'espressione rumpere una condotta qualificata dall'evento materiale che essa causava, uno scindere corpus, una lesione distruttiva, e perciò permanente. Con il termine rupitiae si sarebbe indicato, pur nell'esiguità delle informazioni disponibili, la perdita legata alla distruzione fisica di un oggetto. Ma in dottrina, come è noto, non vi è accordo né sul fatto che le XII Tavole contenessero una norma siffatta né sull'interpretazione da darle se la si ritiene esistente; mentre nei F.I.R.A. viene riportata in Tab. VIII. 5, il Crawford non la riporta nella sua ricostruzione, opportunamente secondo il Cannata ${ }^{89}$, che ritiene difficile parlare di norma generale di danno ${ }^{90}$. Pare, effettivamente, difficile addurre come norma generale di danno, qualunque significato si ritenga di attribuire al termine, la norma sulle rupitiae $^{91}$, per cui, accettando la tesi che il terzo

${ }^{86}$ CORBINO, Il danno qualificato ${ }^{2}$, cit., $59 \mathrm{~s}$.

${ }^{87}$ J. GOTHOFREDUS, Fragmenta leges XII tabularum: sius nunc primum tabulis restitute probationibus notis, Heidelberg 1616.

${ }^{88}$ NATALI, La Legge Aquilia, cit., 2 ss.

89 Osservava CANNATA, Sul testo della lex Aquilia, cit., 27 ss., che contro la tesi che vede in Tab. VIII. 5 una norma generale sul risarcimento del danno si può osservare che in Festo (Rupitias XII significat damnum dederit) rupitias ha forma di accusativo plurale, ma la morfologia della frase esigerebbe il nominativo, in quanto Festo declina sempre i sostantivi che spiega considerandoli elementi della proposizione chiarificatrice. Per quanto riguarda la correzione di rupitias in rupit, che appare del tutto coerente, essa rompe, però, il nesso tra i due passi di Festo, perché se la spiegazione contenuta nel primo si riferisce non a rupitias ma a rupit, può attribuirsi alla norma sul membrum ruptum di tab. 8. 2 invece che alla norma, qualunque essa sia, in cui si poteva leggere il sarcito spiegato nell'altro passo (Sarcito in XII Ser. Sulpicius ait significare 'damnum solvito, praestato'). Anche la spiegazione che Festo e Servio danno di sarcito può riferirsi ad altre norme perché noxiam sarcire compare sia in tab. VIII.10 sia in tab. VIII.14. Inoltre, poichè dall'espressione di D. 9, 4, 2, 1 si servus furtum faxit noxiamve nocuit si ricava che con furtum faxit si sintetizzano tutte le specie di furto previste nelle leggi decemvirali, con noxiam nocuit tutti i casi di danno, quando Festo precisava che rupitias XII significat damnum dederit non poteva riferirsi a una norma generale, perché l'espressione in genere usata nelle XII Tavole era noxiam nocuit. Sussiste, poi, un argomento, per l'autore, che rende assai improbabile che le dodici tavole contenessero una norma generale sul risarcimento dei danni, nella quale la fattispecie sanzionata venisse descritta con l'impiego del verbo rumpere o del suo derivato rupitiae, il fatto che, se l'interpretazione estensiva come corrumpere (D. 9, 2, 27, 13) del rumpere si fosse potuta basare sul corrispondente impiego del verbo rumpere o del suo derivato rupitia nel testo decemvirale, i giuristi non avrebbero mancato di notarlo.

90 Altri autori hanno prospettato delle ipotesi, che, se pur suggestive, appaiono prive di dimostrazione: così M. VOIGT, Die XII Tafeln. I, Leipzig 1883, 721, che ricostruiva in tal modo il versetto: si rupitias faxit vel alienum servum, quadrupedemve pecudem occeslit, noxiam sarcito; VON LUBTOW, Untersuchungen, cit., 22 s., seguito da VALDITARA, Damnum ${ }^{2}$, cit., 4, ritiene che la norma sulle rupitiae avrebbe riguardato la ruptio del servo; E. POLAY, Iniuria types in Roman Law, Budapest 1986, 39, propone una lettura riguardante i soli pecudes: rupitias si quis alterius pecudi iniuria faxsit, sarcito.

${ }^{91}$ pur tenendo conto anche delle glosse noxia ([no]xia, ut Ser. Sulpicius Ru[fus] ait, damnum significat in XII. e sarcito (sarcito in XII Ser. Sulpicius ait significare 'damnum solvito, praestato'). Osservava DAUBE, The Third Chapter, cit., 3 ss., che quando è richiesto semplicemente il risarcimento, le XII Tavole parlano di noxam sarcire, risarcire il danno. Noxa - che rimanda, però, indubbiamente, anche all'istituto della noxae deditio, prevista nel caso dell'actio de pauperie (D. 9, 1, 1 pr.), su cui infra, denoterebbe l'attuale danno o la mancanza prodotta che deve essere riparata; nei casi più seri, riparare il danno non è però abbastanza, ci deve essere in aggiunta una punizione, un dare, una spendita da parte di chi ha offeso. Damnum decidere significherebbe mettersi d'accordo non sull'entità della perdita, ma sull'ammenda da pagare. Per le XII Tavole dunque noxia sarebbe il danno attuale fatto a un oggetto o la perdita attuale prodotta portando via un oggetto, damnum un'ammenda consistente in una restituzione multipla, poena una multa fissa. Damnum nel senso di perdita incorsa alla vittima di un'offesa sarebbe stato introdotto dalla lex Aquilia e solo nel terzo caput. Di recente osserva GALEOTTI, Ricerche, cit., 19 ss., che non si può trarre l'esistenza di una norma generale de damno in Tab. VIII. 5 dalla combinazione delle glosse di Festo, se si tiene conto anche della glossa noxia, in quanto, dalla combinazione fra questa glossa e Lindsay 320: Rupitias in XII significat damnum dederit, avremmo, secondo la Galeotti la seguente concatenazione: noxia=damnum, rumpere $=$ damnum dare, rumpere $=($ noxia $=$ damnum $)$, dare rumpere $=$ noxiam committere/nocere. Il qui rupit, sarcito avrebbe allora valore analogo a qui noxiam commisit (nocuit), sarcito. Per l'autrice, se è plausibile che i termini noxia e damnum fossero 
caput della lex Aquilia non prevedesse originariamente il damnum iniuria datum a schiavi e pecudes, tali danni, a parte l'ossis fractio, non risulterebbero sanzionati, stando alle norme che ci sono pervenute, sino alla successiva estensione del terzo caput in seguito all'interpretatio. Ma nelle prime testimonianze che possediamo di interpretatio della lex Aquilia si prende in considerazione proprio la quasi ruptio di schiavi e pecudes (D. 9, 2, 27, 22) e la ruptio di una pecus (D. 9.2.39 pr.) in caso di aborto, senza che tali beni siano, peraltro, distrutti.

I due passi, che vengono spesso esaminati congiuntamente dalla dottrina, presentano delle considerevoli differenze: oltre all'utilizzo da parte di Bruto del quasi rupto, e di Quinto Mucio del rumpere, occorre rilevare che Bruto parla di una schiava ${ }^{92}$ e di una cavalla che in seguito a un pugno o a un colpo espellono il feto, Quinto Mucio pone l'accento sull'attività del proprietario del fondo volta a scacciare la cavalla, attività che sarebbe di per sé lecita, ma cessa di esserlo nel caso in cui egli usi le percosse o una condotta particolarmente veemente. Il caso prospettato da Quinto Mucio configura, diversamente da quello più generale di Bruto ${ }^{93}$, una fattispecie di pascolo abusivo in un terreno altrui, ponendo dunque una serie di problematiche, inerenti, presumibilmente, ai rapporti tra vicini, non presenti nel passo di Bruto; gli animali potevano arrecare dei danni entrando nel campo altrui e il proprietario del campo poteva scacciarli, ma se, così facendo, provocava loro una ruptio, ne rispondeva ai sensi della lex Aquilia ${ }^{94}$ se superava i limiti della causa di giustificazione. Il proprietario dell'animale, indubbiamente, aveva il dovere di sorvegliarlo, ma il proprietario del fondo, pur avendo il diritto di allontanarlo, doveva farlo con modalità tali da non causargli danni, trattandolo, come afferma Pomponio nel successivo paragrafo, come avrebbe fatto se fosse stato suo

- D. 9, 2, 39, 1: Quamvis alienum pecus in agro suo quis deprehendit, sic illud expellere debet, quomodo si suum deprehendisset, quoniam si quid ex ea re damnum cepit, habet proprias actiones. itaque qui pecus alienum in agro suo deprehenderit, non iure id includit, nec agere illud aliter debet quam ut supra diximus quasi suum: sed vel abigere debet sine damno vel admonere dominum, ut suum recipiat ${ }^{95}$.

equivalenti ai tempi di S. Sulpicio Rufo, non è detto che ciò fosse vero ai tempi dei decemviri, per i quali le sfere semantiche dei due termini non sembrano sovrapporsi del tutto, tanto che i sintagmi noxiam sarcire e damnum decidere designano una stessa situazione, ma valutata da poli opposti. Nell'uno, infatti, noxia è la perdita subita dall'offeso, mentre damnum designa la conseguenza cui è astretto l'offensore. Nello stesso senso, in precedenza, C. PELloso, Studi sul furto nell'antichità mediterranea, Padova 2008, 199 nt. 146 e 147, per il quale noxiam facere è sinteticamente opposto a damnum facere, che significa subire una perdita, così come, sotto il profilo etimologico, la perifrasi noxiam factam sarcire è antitetica al decidere damnum, in cui si farebbe menzione non di una conseguenza negativa che ricade sul soggetto passivo dell'illecito, bensì di una conseguenza negativa, con ricadute sulla sfera personale dell'agente, della condotta tenuta da quest'ultimo. E' lecito per l'autore pensare a noxia come alla conseguenza negativa da illecito (da sanzionare) e a damnum come alla conseguenza negativa in funzione sanzionatoria che ricade - per volontà della civitas - entro la sfera di colui che va sanzionato.

92 Per BIGNARDI, Frangere e rumpere, cit., 46 s., il riferimento alla schiava sarebbe, però, da eliminare per tre motivi: l'uso del termine mulier, il verbo eicere al singolare e il fatto che nella parallela ipotesi poi considerata da Q. Mucio in D. 9, 2, 39 pr. manchi il caso della schiava. Osservavo in un mio precedente articolo, Quasi rupto, quasi rumpere. Dalle XII Tavole ai Digesta, in «Min. Epig. Pap.» 2009-12 (2012) 8 ss., che il termine mulier viene adoperato in riferimento alla schiava in una pluralità di passi (si vedano, ad esempio, D. 9, 2, 9 pr., D. 41, 3, 44, 2, D. 42, 8, 25, 5), e che eiecerit al posto di eiecerint può essere dovuto ai noti problemi a livello paleografico. Quanto al fatto che il caso della schiava manchi nel passo di Q. Mucio, non mi pare si possa parlare di ipotesi parallela: difficilmente il giurista poteva riferirsi anche alla schiava, dal momento che prospetta l'ipotesi di una cavalla che viene scacciata dal fondo altrui nel quale stava pascolando.

${ }^{93}$ Per il Corbino, il fatto che Bruto si riferisca sia alla mulier sia all'equa mostra che non muove da un caso ma ipotizza un problema teorico. Il punto non sembra, peraltro, certo; oltre alla circostanza che non possediamo il responso di Bruto ma solo quanto riferisce Ulpiano, a me sembra difficile che un giurista risalente come Bruto possa avere affrontato il caso solo come problema teorico.

94 V. anche E. GRŪBER, The Roman Law of Damnage to Property, Oxford 1886.

95 Per S. SchIPANI, Responsabilità ex lege Aquilia. Criteri di imputazione e problemi della culpa, Torino 1969, 133 ss., 306 ss., 354, mentre Q. Mucio richiede che venga superato il limite dell'eccesso doloso, Pomponio negherebbe la 
4. Il proprietario del fondo dunque, secondo Pomponio, habet proprias actiones per i danni che l'animale può aver provocato. Vale forse la pena, prima di ritornare al parere di Quinto Mucio, di chiederci quali siano tali azioni; sappiamo che i danni arrecati dagli animali potevano essere sanzionati sin dalle XII Tavole con l'actio de pauperie e con una 'enigmatica' ${ }^{96}$ actio de pastu pecoris

- Ulp. 18 ad ed. D. 9, 1, 1 pr.: Si quadrupes pauperiem fecisse dicetur, actio ex lege duodecim tabularum descendit: quae lex voluit aut dari id quod nocuit, id est id animal quod noxiam commisit, aut aestimationem noxiae offerre. 4. Itaque, ut Servius scribit, tunc haec actio locum habet, cum commota feritate nocuit quadrupes, puta si equus calcitrosus calce percusserit, aut bos cornu petere solitus petierit, aut mulae propter nimiam ferociam 7. Et generaliter haec actio locum habet, quotiens contra naturam fera mota pauperiem dedit: ideoque si equus dolore concitatus calce petierit, cessare istam actionem, sed eum, qui equum percusserit aut vulneraverit, in factum magis quam lege Aquilia teneri, utique ideo, quia non ipse suo corpore damnum dedit

- Ulp. 41 ad Sab. D. 19, 5, 14, 3: Si glans ex arbore tua in meum fundum cadat eamque ego immisso pecore depascam: Aristo scribit non sibi occurrere legitimam actionem, qua experiri possim: nam neque ex lege duodecim tabularum de pastu pecoris (quia non in tuo pascitur) neque de pauperie neque de damni iniuriae agi posse: in factum itaque erit agendum ${ }^{97}$

Nel caso cadano dei frutti dall'albero confinante nel fondo del vicino e questi immisso pecore depascat, secondo Aristone non può essere concessa alcuna legitima actio: né l'actio de pastu pecoris, né l'actio de pauperie, né l'actio ex lege Aquilia, ma si potrà agire in factum. La mancata concessione dell'actio de pastu pecoris sembra dovuta alla circostanza che gli animali hanno mangiato i frutti caduti nel fondo del loro dominus (quia non in tuo pascitur) il che indica che l'actio era esperibile solo in caso di pascolo abusivo nel fondo altrui. Per Aristone il proprietario dei frutti non può esperire neanche l'actio ex lege Aquilia; come è noto, cessabit

legittimità di qualsiasi eccesso. Per C.A. CANNATA, Genesi e vicende della colpa aquiliana, in «Labeo» 17 (1971) 64 ss., in part. 69, Q. Mucio affermava che il proprietario può cacciare l'animale intruso, ma 'col dovuto garbo', Pomponio indicava il perché del limite a tale comportamento, e precisava le modalità del comportamento lecito: occorre espellere l'animale soltanto con gli stessi mezzi che si utilizzerebbero per il proprio. Questa considerazione è notevole, secondo l'autore, perchè è fatto riferimento alla diligentia quam in suis sia pure con uno scopo piuttosto diverso dal solito, in quanto normalmente la diligenza nei propri affari fornisce un'immunità dalla responsabilità e un debitore leggermente negligente nei propri affari non è soggetto in larga misura a una terza parte. Nel nostro caso l'espulsione è consentita in principio perchè non è necessario tollerare il bestiame di qualcun altro, ma nel fare questo, nell'espellerlo, deve essere osservata la stessa diligenza che l'agricoltore usa col proprio bestiame.

${ }^{96}$ Così P. HuVELIN, Études sur le furtum dans le très ancient droit romain, I, Lyon-Paris 1915, 62 nt. 4.

97 Vedi però anche Ulp. 24 ad ed. D. 10, 4, 9, 1: Glans ex arbore tua in fundum meum decidit, eam ego immisso pecore depasco: qua actione possum teneri? Pomponius scribit competere actionem ad exhibendum, si dolo pecus immisi, ut glandem comederet: nam et si glans extaret nec patieris me tollere, ad exhibendum teneberis, quemadmodum si materiam meam delatam in agrum suum quis auferre non pateretur. Et placet nobis Pomponii sententia, sive glans extet sive consumpta sit. Sed si extet, etiam interdicto de glande legenda, ut mihi tertio quoque die legendae glandis facultas esset, uti potero, si damni infecti cavero. Ulpiano riporta il parere di Pomponio secondo cui nel caso i frutti siano caduti nel fondo del vicino si può esperire l'actio ad exhibendum se l'animale è stato immesso dolosamente nel fondo (immisso pecore) perché se ne cibasse; Ulpiano (o forse i compilatori) approva e precisa che questo vale anche se la glans consumpta sit. Se extat, si applicherà anche l'interdetto de glande legenda, in riferimento al diritto del proprietario di raccogliere i frutti che da un proprio albero (confinante) sono caduti nel fondo del vicino, recandosi in tale fondo a giorni alterni, come leggiamo nel noto tab. VII. 10. Plinius n.h. 16, 5, 15: Cautum est - lege XII tab., ut glandem in alienum fundum procidentem liceret colligere. (si vedano anche Ulp. 71 ad ed. D. 43,28,1: Ait praetor: Glandem, quae ex illius agro in tuum cadat, quo minus illi tertio quoque die legere auferre liceat, vim fieri veto. Glandis nomine omnes fructus continentur, Gai 4 ad 1. XII Tab. D. 50, 16, 236, 1: Glandis appellatione omnis fructus continetur, ut Iavolenus ait, exemplo graeci sermonis, apud quos omnes arborum species $\alpha \kappa \rho$ ó $\rho v \alpha$ appellantur). 
igitur Aquiliae actio, quemadmodum, si quadrupes damnum dederit ${ }^{98}$, perché l'animale non è capace di iniuria: nec enim potest animal iniuria fecisse quod sensu caret ${ }^{99}$. Non è, inoltre, possibile esperire $1^{\prime}$ actio de pauperie ${ }^{100}$, altra azione antichissima prevista dalle XII Tavole ${ }^{101}$; Aristone non spiega il motivo, che sembrerebbe da ravvisare nella mancanza del requisito che l'animale avesse tenuto un comportamento contra naturam ${ }^{102}$, in quanto tale non può essere qualificato il mangiare i frutti, e nella mancanza del requisito dello sconfinamento spontaneo dell'animale, in quanto dall'inciso ego immisso pecore si ricaverebbe un comportamento doloso o colposo del proprietario del gregge, che avrebbe spinto o almeno permesso agli animali di cibarsi delle ghiande ${ }^{103}$.

98 Ulp. 18 ad ed. D. 9, 2, 5, 2 .

${ }^{99}$ Ulp. 18 ad ed. D. 9, 1, 1, 3 .

${ }^{100} \mathrm{Si}$ vedano S. Monossohn, Actio de pauperie im System des römischen Noxalrechtes, Berlin 1911; B. BIONDI, Actiones noxales, in «Annali Palermo» 10 (1925) 1 ss.; U. RoBBE, L'actio de pauperie, in «RISG» 7 (1932) 327 ss.; ID., s.v. Pauperies, in «NNDI» XII, Torino 1965, 730 ss.; J. KERR WYLIE, Actio de pauperie. Dig. Lib. IX, tit. 1, in Studi S. Riccobono, IV, Palermo 1936, 459 ss.; G. BRANCA, Danno temuto e danno da cose inanimate nel diritto romano, Padova 1937, 296 ss.; 458 ss.; E. CARRELLI, Plinio Nat. Hist. 18. 3.12 e il delitto di danneggiamento alle messi nel sistema delle XII tavole, in «Annali Bari» n.s. 2 (1939) 3 ss.; A. VISCONTI, Pauperiem facere (note ai cc. 326 e 328 dell'Editto di Rotari e al tit. XV dell'Editto perpetuo), in Studi A. Solmi, I, Milano 1941, 155 ss.; B. NICHOLAS, Liability for Animals in Roman Law, in «Acta juridica» I (1958) 185 ss.; L. MüLLER, s.v. Pauperies, in Real-Enzyklopädie der klassischen Altertumswissenschaft, suppl. 10, Stuttgart 1965, cc. 521 ss.; A. WATSON, The Original Meaning of 'Pauperies', in «RIDA» 17 (1970) 357 ss.; J. MACQUERON, Les dommages causés par des chiens dans la jurisprudence romaine, in Flores legum H.J. Scheltema oblati, Groningen 1971, 133 ss.; J. MODRZEJEWSKI, Ulpien et la nature des animaux, in Colloquio italo-francese. La filosofia greca e il diritto romano. Roma 14-17 aprile 1973, I, Roma 1976, 177 ss.; B.S. JACKSON, Liability for Animals in Roman Law: an Historical Sketch, in «The Cambridge Law Journal» 37 (1978) 122 ss.; H. ANKUM, L'a. de pauperie e l'a. legis Aquiliae dans le droit romain classique, in Studi C. Sanfilippo, II, Milano 1982, 11 ss.; J. TrIANTAPHYLlOPOULOS, 'Contra naturam', in Sodalitas. Scritti A. Guarino, III, Napoli 1984, 1415 ss.; M.V. GIANGRIECO PESSI, Appunti in tema di danneggiamento causato da animali in diritto romano dalle XII Tavole ad Ulpiano, Roma 1994; EAD., Ricerche sull'actio de pauperie. Dalle XII Tavole ad Ulpiano, Napoli 1995; M. POLOJAC, Actio de pauperie - domestic and wild animals, in I. PIRO (a cura di), Règle et pratique du droit dans les réalités juridiques de l'antiquité. Atti della $51^{\text {a }}$ Sessione della SIHDA, Crotone-Messina 16-20 settembre 1997, 1999, 463 ss.; EAD., L'actio de pauperie ed altri mezzi processuali nel caso di danneggiamento provocato dall'animale nel diritto romano, in «Ius Antiquum» VIII (2001) 81 ss.; EAD., Actio de pauperie and Liability caused by Animals in Roman Law, Belgrade 2003.; P.P. ONIDA, Studi sulla condizione degli animali non umani nel sistema giuridico romano ${ }^{2}$, Torino 2012, 338 ss.

${ }^{101}$ Il Cannata cita la pauperies come esempio di danneggiamento non distruttivo che era rimasto in vigore dai tempi delle XII Tavole ed avrebbe pertanto potuto giustificare il fatto che la lex Aquilia non se ne occupasse, ma, oltre al fatto che nel caso di pauperies si tratta di danneggiamento provocato dall'animale e non all'animale, non sembra condivisibile che il danneggiamento da pauperies dovesse essere sempre non distruttivo

${ }^{102} \mathrm{Si}$ discute, come è noto, in dottrina se il requisito del contra naturam fosse già previsto nelle XII Tavole, se sia stato introdotto dalla giurisprudenza dei Severi oppure inserito dai giustinianei. P. F. GIRARD, Les actions noxales, in «NRH», 11 (1887), 409 ss., aveva ritenuto che l'actio de pauperie fosse concessa inizialmente per qualsiasi tipo di danneggiamento, e solo in un secondo momento fosse stata limitata ai comportamenti contra naturam. Per A. FLINIAUX, Une vieille action du droit romain: l'action de pastu, in Mélanges Cornil, I, Paris 1926, 245 ss., in part. 256 e ivi nt. 3, "cette distinction entre le dommage causé par l'animal secundum naturam et celui causé contra naturam n'a pu se dégage qu'à une époque où a été reconnu le principe de l'imputabilité, c'est-à-dire à la fin de la République”. Per GIANGRIECO PESSI, Ricerche, cit., il contra naturam sarebbe di Ulpiano, in quanto, al periodo delle XII tavole, data l'accentuata rilevanza delle necessità correlate alla coltivazione della terra, è probabile che il danneggiamento da animale, comunque provocato, dovesse comportare il diritto del soggetto offeso al risarcimento. Per ROBBE, L'actio de pauperie, cit., 327 ss; ID., s.v. Pauperies, cit., 731; KERR WYLIE, Actio de pauperie, cit., 471 ss.; BRANCA, Danno temuto, cit., 298 e nt. 2, si tratta di una rielaborazione giustinianea. Osserva di recente ONIDA, Studi sulla condizione, cit., 361 ss., che proprio nell'età arcaica, quando la concezione del diritto appariva fortemente intrisa di elementi sacrali e l'economia era prevalenteente agro-pastorale, vi erano già (e a maggior ragione) tutte le premesse per la formazione di un principio legato alla natura animalium.

${ }^{103}$ FLiniauX, Une vieille action, cit., 256: "Pour cequi est d'abord de l'actio de pauperie, c'est cefait qu'elle se trouve nécessairement écartée toutes les fois que l'animal qui a cause le dommage a été poussé par un tiers à le commetre"; RoBBE, L'actio de pauperie, cit., 327 ss.; ID., s.v. Pauperies, cit.,730 ss.; J. KERR WYLIE, Actio de pauperie, cit., 518 s.: "The reason for the exclusion of the actio de pauperie is that here we have a case of non-natural pauperies and that the consumption of the fruits by the cattle was attributable to my act of immissio alone"; POLOJAC, L'actio de 
Se nel caso previsto in D. 9, 2,39 pr. Pomponio non intendeva probabilmente riferirsi all'esperimento da parte del proprietario del fondo dell'actio de pauperie per l'assenza del requisito del comportamento contra naturam e dello sconfinamento spontaneo dell'animale, occorre chiedersi se intendesse, invece, riferirsi all'actio de pastu pecoris. Tale azione sarebbe esperibile se non riteniamo la condotta del proprietario requisito necessario per l'esperimento dell'azione $^{104}$, e se riteniamo, con il Fliniaux ${ }^{105}$ e la dottrina prevalente, che riguardasse non solo le pecore ${ }^{106}$, ma più in generale il bestiame. Sembra di questo avviso anche quella parte della dottrina, sia risalente ${ }^{107}$, sia recente ${ }^{108}$, che parla di actio de pastu o di actio de pastu aggravata per il caso in cui il proprietario avesse portato il proprio bestiame a pascolare noctu e furtim nel terreno altrui, ricordato nelle XII Tavole secondo la testimonianza di

- Plin. n.h. 18,3,12: Frugem quidem aratro quaesitam noctu furtim pavisse ac secuisse XII tabulis capital erat, suspensumque Cereri necari iubebant, gravius quam in homicidio convictum, impubem praetoris arbitratu verberari noxiamve duplionemve decerni ${ }^{109}$.

pauperie, cit., 81 ss.; GIANGRIECO PESSI, Ricerche, cit., 170 ss.; E. CAIAZZO, Lex Pesolania de cane, in «Index» 28 (2000) 279 ss., in part. 295 n.32, per la quale non si potrebbe esperire l'actio de pauperie "perchè la causa dell'evento dannoso è da ricercarsi nell'azione del proprietario del gregge che spinge le pecore a cibarsi delle ghiande".

${ }^{104}$ Per la necessità della condotta del proprietario JACKSON, Liability, cit., 127: "on the basis of such scraps of information as have been preserved, it appears likely that only deliberate depasturation was actionable"; 137: 1'actio de pastu pecoris "depended on proof of dolus, or assuming some liberality in the interpretation of immettere pecus, culpa”. Per GIANGRIECO PESSI, Ricerche, cit., 170 ss., nell'identificazione o meno del comportamento dell'animale come causa dell'evento dannoso sarebbe da ritrovarsi l'elemento di differenziazione tra l'actio de pauperie e l'actio de pastu: nell'actio de pastu sarebbe necessaria la responsabilità dell'uomo in relazione al comportamento posto in essere dagli animali (la conduzione al pascolo abusivo) mentre nell'actio de pauperie si tratterebbe di un comportamento spontaneo dell'animale. Sembra ritenere necessaria l'immissio per l'esperimento dell'actio de pastu anche CAIAZZO, Lex Pesolania de cane, cit., 295 n.32, per la quale secondo Aristone non si potrebbe esperire tale azione perché mancherebbe l'immissio del proprio bestiame nel fondo altrui. Non del tutto chiara l'opinione di FLINIAUX, Une vieille action, cit., 263 s., il quale, da un lato, afferma, chiedendosi quali siano le propriae actiones cui allude Pomponio in D. 9.2.39.1 (che sta parlando della fattispecie descritta da Quinto Mucio), che "il s'agit de toutes les actions qui qui peuvent être intentées à l'occasion d'un dommage quelconque (et non pas seulement, croyons-nous, en vertu d'un dommage resultant du pastus) que des animaux peuvent commetre, alors qu'ils se trouvent sur le fonds d'autrui. Parmi ces actions figure au premier rang notre actio de pastu à la quelle il convient d'ajouter l'actio de pauperie, comme ce serait le cas, par exemple, si, sans provocation de la part de l'homme, l'animal avait blessè un autre animal appartenant au propriétaire du fonds, l'action de la loi Aquilia dans le caso ù l'acte dommageable de l'animal a été provoqué par l'agissement d'un homme", dall'altro (281), che l'actio de pastu "implique nécessairement un acte du maître de l'animal, qui consiste dans le fait de pousser son tropeau: immettere pecus".

${ }^{105}$ Per FliniauX, Une vieille action, cit., 281 s., l'actio de pastu 's'applique à tous les animaux qui pascuntur, c'est à dire qui se nourissent normalment en pâturant (pecora, pecudes), par conséquent aussi bien à des quadrupèdes, comme les bœufs, les chevaux, les ânes, les mulets, les moutons, les chèvres, les porcs, qu'à des bipèdes, poulets, oies, etc'.

${ }^{106}$ In tal senso POLOJAC, L'actio de pauperie, cit.; v. anche Actio de pauperie: anthropomorphism and rationalism, in «Fundamina» 18.2 (2012) 119 ss.

${ }^{107}$ VoIGT, Die XII Tafeln, cit., 538, aveva parlato per il passo di Plinio di un caso di pastu pecoris aggravato; per CARrelli, Plinio Nat. Hist. XVIII 3 13, cit., 1 ss., i decemviri avrebbero isolato un caso di pastu pecoris che, per le particolari circostanze in cui si era verificato, e per le più dannose conseguenze che aveva avuto, appariva di molto maggiore gravità, e in luogo della pena pecuniaria, avrebbero comminato la pena capitale.

${ }^{108}$ VALDITARA, Damnum ${ }^{2}$, cit., 3 e ivi nt. 3; M.F. CURSI, La formazione delle obbligazioni ex delicto, in «RIDA» 58 (2011) 143 ss.

${ }^{109}$ L'antichissima norma che prevede l'uccisione di colui che furtim frugem pavisse ac secuisse, comportamento gravissimo e sanzionato nelle XII Tavole non solo con la morte ma anche con la consacrazione a Cerere, persegue, però, non solo la lesione di un interesse economico ma anche l'oltraggio alla divinità, dea della terra. La fattispecie è, indubbiamente, diversa rispetto a quella in cui gli animali si fossero introdotti spontaneamente nel terreno altrui, caso in cui, pur non conoscendosi la sanzione stabilita, doveva essere probabilmente applicata una pena pecuniaria. Molteplici le opinioni espresse in dottrina sulla qualificazione della fattispecie prevista, che sembra al confine fra il furto e il danneggiamento: mentre il Voigt aveva ritenuto che l'attività di frugem pavisse concretasse un caso di pastus pecoris aggravato e il frugem secuisse un caso di furto aggravato, il Karlowa parlava in tutti e due i casi di damnum iniuria datum con le stesse caratteristiche di quello in seguito previsto dalla lex Aquilia, per l'Huvelin, il 
Se riteniamo che l'actio de pastu fosse riferita in generale al bestiame e non solo alle pecore, e fosse esperibile anche in caso di comportamento spontaneo dell'animale ${ }^{110}$, nel caso preso in esame da Quinto Mucio il proprietario del fondo avrebbe, dunque, potuto esperire l'actio de pastu se la cavalla avesse provocato dei danni, ma poteva essere convenuto con la lex Aquilia se, usando non solo la violenza, ma anche un agere consulto vehementius per allontanare l'animale, gli avesse procurato una ruptio. Avrebbe, infatti, superato, secondo Quinto Mucio, i limiti dell'esimente dell'esercizio del proprio diritto ${ }^{111}$ non solo nel caso avesse usato le percosse ma anche un agere consulto vehementius, perché, percuotendo o agendo consulto vehementius, la sua condotta lesiva non poteva essere giustificata.

5. Dal passo di Quinto Mucio sembrerebbe, pertanto, ricavarsi non solo che il procurato aborto costituisca una ruptio della cavalla ${ }^{112}$, ma anche che questa ruptio possa verificarsi, nel caso dell' agere consulto vehementius, in assenza del requisito del damnum corpore datum, considerato dalla dottrina prevalente in origine necessario per la concessione dell'actio diretta ex lege Aquilia. Il problema è stato ampiamente dibattuto in dottrina: per l'Albanese ${ }^{113}$ aut consulto vehementius agisse sarebbe stato aggiunto dai Compilatori perché Quinto Mucio non potrebbe aver pensato alla concessione di un'azione diretta indifferentemente nell'ipotesi del danno arrecato corpore (si percussisset) e nell'ipotesi del danno arrecato non corpore (aut consulto vehementius egisset $)^{114}$. Mentre per altra parte della dottrina ${ }^{115}$ non sarebbe corretto

quale ritiene che l'informazione di Plinio possa derivare da Masurio Sabino, si tratta indiscutibilmente di un caso di furto, come provato dall'impiego dell'avverbio furtim, strettamente imparentato al termine furtum. Per il Mommsen si trattava in entrambi i casi di furto aggravato, l'unico caso, insieme al delitto di fruges excantare e segetem alienam pellicere, in cui le XII Tavole avrebbero colpito con pena pubblica il furto. Per il Carrelli occorre tener conto del fatto che il raccolto poteva essere mandato a male non solo immettendo il bestiame nel campo altrui e lasciandolo pascolare - nel qual caso, sia pure indirettamente, attraverso il nutrimento si sarebbe potuto parlare di una vera e propria apprensione dei frutti da parte del proprietario, e quindi di furto - ma anche quando l'animale immesso scorrazzando fra i solchi potesse fare danni ben maggiori che limitandosi a stare anche più a lungo al pascolo. Come nell'actio de pastu pecoris sarebbero rientrati tutti i danni che l'animale aveva compiuto pascolando, sia per il fatto di essersi nutrito dei frutti, sia per il fatto di essersi aggirato per il fondo producendovi danni vari, così doveva avvenire nei confronti di questa disposizione, con la quale si colpiva chiunque avesse volontariamente introdotto bestiame in un fondo altrui coltivato a cereali, sia che ciò venisse fatto con l'intenzione specifica di ricavarne un lucro, nutrendo il proprio gregge a spese del vicino, sia che ciò venisse fatto con l'intenzione specifica di mandare a male il raccolto. Per quanto riguarda l'ipotesi del secuisse, non è materialmente possibile, per l'autore, determinare se i decemviri se la siano prospettata tenendo particolarmente presente il caso di chi era andato a mietere spighe nel fondo altrui con l'intenzione di asportarle, di chi fruges maturas subsecuit, o il caso di chi era penetrato nel fondo altrui per mietervi un raccolto ancora in erba, con l'intento di impedire che il raccolto giungesse a maturazione; il delitto, sarebbe, però, in ogni caso, un delitto di danneggiamento. Pur non potendoci soffermare su questo aspetto, sembra importante sottolineare che non può trattarsi di due delitti distinti perché il testo parla di pavisse ac secuisse, dunque per realizzare la fattispecie dovevano essere tenute entrambe le condotte.

${ }^{110}$ In tal senso CARRELLI, Plinio Nat. Hist. 18. 3. 12, cit., 4 ss.

${ }^{111}$ Per S. GALEOTT, Ricerche sulla nozione di damnum II, I criteri di imputazione del danno tra lex e interpretatio prudentium, Napoli 2016, 103, si tratta, invece, di un'ipotesi inquadrabile come 'eccesso di difesa'.

${ }^{112}$ Per VALdiTARA, Superamento dell'aestimatio rei, cit., 271 s. e nt. 17, la discussione dei veteres ricordata testualmente da Pomponio non si incentrava sulle modalità di stima del danno, né tanto meno sulla considerazione del valore del puledro o del servo perduti, ma semplicemente sul fatto se si potesse considerare rupta la cavalla o la schiava onde applicarsi dunque il capo III della lex, nell'ambito di quella che appare ancora una pura rei aestimatio. Mi pare però che Quinto Mucio non discuta se possa considerarsi rupta la cavalla, circostanza che dà per scontata, ma piuttosto in quali casi scacciarla dal terreno possa considerarsi esercizio legittimo del proprio diritto e in quali no.

${ }^{113}$ B. AlBanESE, Studi sulla legge Aquilia, in «AUPA» 21 (1950) 5 ss.

${ }^{114}$ FliniaUX, Une vieille action, cit., 261 s., ritiene che aut consulto vehementius egisset o l'intera frase si percussisset aut consulto vehementius egisset non si trovasse nel testo originale di Quinto Mucio e sia stata introdotta dai Compilatori. (vedi anche per l'interpolazione S. RICCOBONO, Communio e comproprietà, in Essays in legal History read before the International Congress of Historical Studies held in London in 1913, Oxford 1913, 75 nt. 3). Per F. SCHULZ, Storia della giurisprudenza romana, trad. G. NOCERA, Firenze 1968, 147 nt.1 (la nota non appare nella versione inglese), Bruto sembra avere interpretato più liberamente il rumpere del III caput, ma il passo è evidentemente alterato, perché il giurista doveva aver proposto un'actio in factum. VON LUBTOW, Untersuchungen, cit., 167 s., 
affermare che manchi il contatto corpore, in quanto agere detto di animali più che spaventarli per spingerli a correre via per proprio conto, designerebbe il condurli, cioè un diretto contatto fisico di tirare, spingere, pungolare, secondo una recente teoria ${ }^{116}$ occorrerebbe riconsiderare la stessa nozione di damnum corpore datum, con la quale i giuristi non si sarebbero riferiti, come tradizionalmente ritenuto, alla necessità di un contatto diretto e immediato tra offensore e bene offeso, ma all'assoluta certezza della riferibilità dell'evento al comportamento, 'che può estrinsecarsi sia attraverso una relazione materiale e diretta tra condotta ed evento, sia attraverso un comportamento che presenti nella sua realizzazione elementi idonei a ricondurre con immediatezza e certezza l'evento dannoso all'autore della condotta (consulto e vehementius) ${ }^{117}$. Mi pare non si possano, però, escludere i sospetti di interpolazione su D. 9, 2, 39 pr. avanzati dall'Albanese, il quale aveva ritenuto che i Compilatori, nel loro lavoro di eliminazione della distinzione classica fra danni dati corpore e non corpore e della connessa actio utilis, avrebbero soppresso anche nel nostro passo ogni accenno al regime classico, ma anziché procedere, come negli altri casi, alla sostituzione dell'actio utilis con quella in factum, avrebbero ricompreso più sbrigativamente sotto la generica tutela della lex Aquilia anche il caso del danno non corpore costituito dall'allontanamento violento dell'animale, ma senza materiale contatto. Tali sospetti appaiono avvalorati anche dal contrasto che sembra emergere tra il passo di Quinto Mucio e il noto passo in cui Gaio afferma che viene concessa un'actio utilis quando il danno non è dato corpore suo, ma alio modo, includendo tra gli esempi quello in cui iumentum tam vehementer egerit, ut rumperetur:

- Gai 3, 219: Ceterum placuit ita demum ex ista lege actionem esse, si quis corpore suo damnum dederit; ideoque alio modo damno dato utiles actiones dantur, veluti si quis alienum nomine aut pecudem incluserit et fame necaverit, aut iumentum tam vehementer egerit, ut rumperetur....

suppone che Mucio abbia concesso l'actio directa per l'ipotesi delle percosse e l'actio utilis per il vehementer agere e che i rielaboratori abbiano soppresso il riferimento all'actio utilis.

${ }^{115}$ Così SCHIPANI, Responsabilità, cit., 134 ss. Per P. ZiliotTo, L’imputazione del danno aquiliano. Tra iniuria e damnum corpore datum, Padova 2000, 194 ss., si concede l'actio legis Aquiliae in assenza di un rapporto di causalità immediata fra condotta ed evento lesivo sulla base della considerazione dell'elemento soggettivo - consulto cioè sull'esistenza dell'iniuria

${ }^{116}$ PIRO, Damnum corpore suo, cit., 72 ss. Per F. LA RosA, Il valore originario di iniuria nella lex Aquilia, in «Labeo» 44 (1998) 366 ss., in part. 375 s., il damnum corpore datum previsto dalla lex Aquilia è un danneggiamento compiuto con atti di violenza fisica.

${ }^{117}$ Con l'espressione consulto vehementius agere si sottolineerebbe, pertanto, l'illiceità del comportamento ravvisata in un incitamento volutamente eccessivo, sproporzionato per intensità e veemenza rispetto al fine di espellere la cavalla dal fondo. Per BIRKS, Doing, cit., 39 nt. 25, 'D. 9.2.39 may reveal, in the word consulto, that early on a jurist might allow intent to filter into the question whether the defendant had done the arm'. Secondo BIGNARDI, Frangere e rumpere, cit., 53 ss., anche per Quinto Mucio, come per Bruto, è solo dalla connotazione violenta del comportamento che sorge la responsabilità. Tuttavia, nel parere di Mucio sono presenti punti di riferimento che non coincidono con quelli ai quali si era riallacciato Bruto, che denuncerebbero avvenuta (o in fieri) una profonda evoluzione sia nel modo di intendere la legge, sia in ordine al significato o alla funzione degli elementi richiesti, in particolare per quanto riguarda il modo di intendere la funzione svolta dal termine iniuria. La risposta di Quinto Mucio pone sullo stesso piano percutere e consulto vehementius agere; mentre con percutere il giurista si muove nell'alveo interpretativo che già si era colto in Bruto, con consulto vehementius agere dimostra di operare anche e parallelamente secondo un nuovo criterio di valutazione. Il rumpere iniuria non deriverebbe più solo dalla natura violenta del comportamento, ma si identificherebbe in una condotta che seppure non connotatata dalla violenza, è volutamente tenuta anche quando, in relazione alla situazione specifica, è idonea a provocare un danno qualificabile come ruptum. Il consulto vehementius riferito all'agere sposterebbe sul piano dell'atteggiamento psicologico il carattere illecito che nel percutere è insito nella condotta; l'alternativa prospettata da Quinto Mucio conterrebbe già, seppure in nuce (ma vedi D. 9, 2, 31 pr.) quello spostamento dell'interpretazione di iniuria dal piano oggettivo a quello soggettivo. 
Una parte della dottrina ritiene però che Gaio e Quinto Mucio, pur usando espressioni simili, potrebbero non riferirsi alla stessa fattispecie ${ }^{118}$, in quanto in Gai 3, 219 non si fa alcun cenno all'espulsione del feto da parte di una cavalla, ma solo al danneggiamento consistente in una ruptio del cavallo (iumentum tam vehementer egerit, ut rumperetur) dovuta ad un'attività che potrebbe, diversamente da quella consulto esaminata da Quinto Mucio, consistere anche semplicemente, come ritiene lo Schipani ${ }^{119}$, nell'aver sfiancato l'animale, nell'averlo fatto correre così tanto da provocargli una ruptio.

Se dubbi permangono sull'esistenza del requisito del contatto corpore nella fattispecie dell'agere consulto vehementius prospettata da Quinto Mucio, tale requisito, tradizionalmente inteso, potrebbe, peraltro, essere considerato mancante anche nel caso preso in esame da Bruto, se riteniamo, seguendo la tesi proposta dalla Bignardi, e poi accolta dal Cannata, che egli considerasse oggetto ruptum il feto; ipotesi che viene, però, oggi respinta con decisione sia dal Corbino sia dal Valditara, per i quali sia Bruto sia Quinto Mucio affrontano senza dubbio il problema dal punto di vista di una ruptio causata alla donna o alla cavalla. Appare allora, forse opportuno riprendere in considerazione la tesi della Bignardi, la quale, partendo dall'idea che l'oggetto ruptum per Bruto fosse il feto, osservava che il giurista ben poteva porsi, valutando l'ipotesi dell'aborto, nella prospettiva di considerare il feto sotto la specie di un bene futuro, tenendo conto del noto

- Ulp. 17 ad Sab. D. 7, 1, 68 pr.: Vetus fuit quaestio, an partus ad fructuarium pertineret: sed Bruti sententia optinuit fructuarium in eo locum non habere: neque enim in fructu hominis homo esse potest. hac ratione nec usum fructum in eo fructuarius habebit. quid tamen si fuerit etiam partus usus fructus relictus, an habeat in eo usum fructum? et cum possit partus legari, poterit et usus fructus eius ${ }^{120}$

\footnotetext{
${ }^{118}$ Ritiene, invece, si tratti della stessa fattispecie A. CORBINO, Actio directa, actio utilis e actio in factum nella disciplina giustinianea del danno aquiliano, in Studi G. Nicosia, III, Milano 2007, 1 ss., in part. 23, per il quale anche in D. $9,2,27,22$ e D. 9, 2, 39 pr. è oggetto di considerazione la corruzione di un animale a seguito dello sforzo al quale è stato sottoposto, che Gaio in 3, 219 comprendeva tra i casi che davano luogo all'actio utilis. Difficilmente, pertanto, i nostri passi potrebbero essere intesi da un punto di vista giustinianeo come riferiti ad un'azione diversa da quella utile, come indicherebbero la presenza del quasi per Bruto e del vehementius agere per Q. Mucio, che discutevano probabilmente in termini di semplice concessione o diniego dell'azione diretta, che Bruto sembrerebbe avere accordato in virtù di un'assimilazione tout court del fatto in oggetto al rumpere legislativo, e Q. Mucio sulla base di un'assimilazione limitata all'ipotesi di un carattere violento dell'azione. La concessione nella fattispecie di un'actio utilis sembrerebbe la conseguenza di una mediazione successiva, poi accolta dalla giurisprudenza in età imperiale (come sembrerebbero indicare l'allusione alla fattispecie già nel testo gaiano iumentum tam vehementer egerit ut rumperetur - e il conforme inquadramento che ne avrebbero poi fatto i compilatori in I. 4, 3, 16).

${ }^{119}$ Per SCHIPANI, Responsabilità, cit., 134 ss., il contrasto fra i due passi non sarebbe, peraltro, determinante: perché in Gaio si considera un'ipotesi di rumpere costituita dallo sfiancare l'animale, mentre il rumpere di Quinto Mucio è in stretta connessione con il precedente costituito da D. 9, 2, 27, 22, che avrebbe operato 'la sussunzione del fatto aborto all'interno del concetto legislativo del rumpere'. I due fatti sarebbero, quindi, diversi: quello considerato da Quinto Mucio non sarebbe uguale a quello "prospettato come paradigmatico esempio di applicazione dell' actio utilis", a proposito del quale, comunque, da un lato si potrebbero riaprire dubbi sull'interpretazione dell'alio modo, dall'altro si potrebbe osservare che il nesso materiale con la condotta, anche se questo implicasse un contatto fisico con l'animale, sarebbe elastico ed aperto a diverse interpretazioni. Si veda, anche, S. SCHIPANI, Lex Aquilia, culpa. Responsabilità, in F. MILAZZo (a cura di), Illecito e pena privata in età repubblicana (Atti del Convegno di diritto romano - Copanello 1990), Napoli 1992, 133 s.

${ }^{120}$ Ritiene VALDITARA, In tema, cit., 204 nt. 51, che nulla abbia a che vedere con il tema in questione D. 7, 1, 68 pr., perché si presuppone che il concepito sia già nato. Sembra, peraltro, evidente che né nel saggio della Bignardi, come risulta da quanto riportato in testo, né nel mio, Quasi rupto, cit., 8 ss., in part. 13, richiamato dal Valditara, si intendesse che in D. 7, 1, 68 pr. e D. 9, 2, 27, 22 si prenda in considerazione lo stesso caso. Come mette in evidenza la Bignardi (42) D. 7, 1, 68 pr. 'è prova che Bruto aveva ben presenti i problemi relativi alle vicende legate alla riproduzione di persone o animali oggetto di dominio. $E$ anche se in questa occasione l'ipotesi prospettata riguarda non il feto ma il già nato, ciò non di meno risulta con sufficiente chiarezza che la prospettiva secondo la quale si muove il giurista è quella di considerare comunque il concepito come un
} 
Per la Bignardi Bruto avrebbe qualificato l'evento per mezzo del verbo tipico della legge, collegandolo direttamente al sorgere della responsabilità: il danno, morte del feto, sarebbe direttamente riferito al comportamento, e stabilendo con teneri quasi rupto $\langle$ fetu $\rangle$ (seguendo lo scolio attribuibile secondo Heimbach all'indice di Doroteo ${ }^{121}$ ) una correlazione diretta fra l'evento e il riconoscimento della responsabilità, si sarebbe posto l'accento sull'esito finale al quale collegare la condotta. Appare allora opportuno esaminare

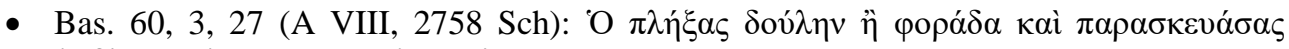

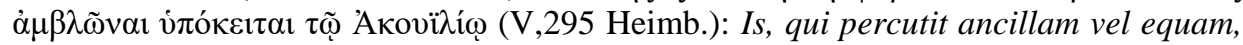
atque ita efficit, ut abortum faciat, tenetur Aquilia

e lo

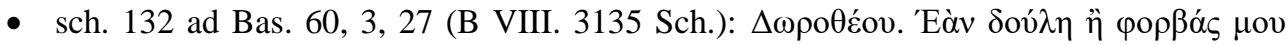

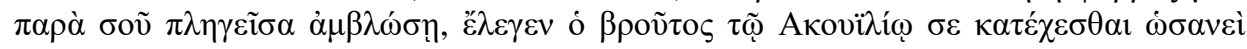

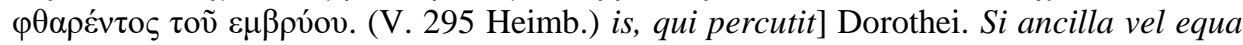
mea a te percussa abortum fecerit, Brutus dicebat te Aquilia teneri, quasi rupto foetu.

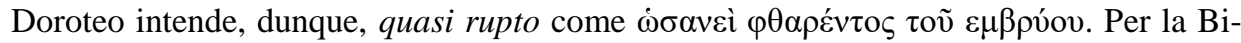
gnardi, alla luce di quanto lo stesso Bruto afferma in D. 7, 1, 68 pr., sia pure espresso a diverso proposito, il quasi, usato come il greco $\omega \sigma \alpha v \varepsilon i ́$ - quindi nel senso di 'quasi' e non nel senso di 'in quanto'- potrebbe essere dovuto alla natura peculiare del bene distrutto, bene solo potenziale: l'eliminazione di un bene, ancora non venuto in essere, non poteva essere indicata come un ruptum, ma come un quasi ruptum. Come evidenziava il Cannata nel suo primo lavoro ${ }^{122}$, l'oggetto ruptum potrebbe essere la cavalla ${ }^{123}$, ma anche, basandosi sullo scolio di Doroteo, il feto, 'non considerato essere umano o pecus, ma cosa autonoma rispetto alla madre'124. L'autore in un primo tempo aveva preferito la prima soluzione, ma in seguito, dopo le osservazioni della Bignardi ${ }^{125}$, ha cambiato parere, ritenendo che l'oggetto ruptum non potesse essere la cavalla (o la schiava), alla quale non sarebbe applicabile il primo caput della lex Aquilia perchè non è stata uccisa, e neanche, secondo la sua teoria, il terzo, in quanto non fa parte delle ceterae res e non è stata rupta, cioè eliminata mediante ruptio, ma il feto, parte della madre e allo stesso tempo res autonomamente individuabile. La diffusa considerazione del feto - nel pensiero giurisprudenziale - come parte della madre, come portio viscerum esclude, invece, per il Corbino e per il Valditara, la possibilità che si vedesse il danno nel feto perduto; anche per il Corbino, se in discussione fosse stata la soppressione del feto, la questione avrebbe riguardato non una ipotesi di ruptio ma un'ipotesi di occisio, in particolare una morte 'occasionata' ${ }^{126}$. Non si può, però, mancare di rilevare che l'aborto, anche posto in essere in maniera

bene'. Bruto potrebbe aver ritenuto il concepito come un bene futuro, 'un bene, in relazione al quale si dovevano definire e determinare le aspettative giuridiche ed economiche, anche se autonomamente solo dopo il distacco dalla madre', usando le parole della Bignardi.

${ }^{121}$ F. BRANDSMA, Dorotheus and his Digest Translation, Groningen 1996, 51, non ha dubbi sull'attribuzione dello scolio a Doroteo: per l'autore l'interpretazione data nello scolio di Doroteo sembra, peraltro, 'inconsistent' con D. 9 , 2, 39 pr., con quanto affermato da Mucio.

${ }^{122}$ CANNATA, Sul testo, cit., 25 ss.

${ }^{123}$ e allora l'espressione quasi rupto, maschile o neutra, andrebbe intesa come generale e corrispondente a 'in quanto vi è stato un rumpere', realizzando il provocato aborto un ferimento della madre, e vedendo il ferire come un rumpere.

${ }^{124} \mathrm{~L}$ 'autrice riteneva non insormontabili le ragioni che avevano indotto il Cannata inizialmente a rigettare tale interpretazione - e cioè che Bruto avrebbe dovuto ritenere il feto una cosa autonoma rispetto alla madre, o comunque non appartenente al genus materno - e che il collegamento di rumpere con il feto diluirebbe il nesso di causalità sul quale poggia la responsabilità ex lege Aquilia.

${ }^{125}$ BIGNARDI, Frangere e rumpere, cit., 11 ss.; EAD., Gai 3.219 e il principio del damnum corpore datum, in «AG» 220 (2000) 487 ss.

${ }^{126}$ Per Cannata Bruto avrebbe potuto anche ritenere che il feto, entità vivente, fosse stato in realtà ucciso, e considerare applicabile il primo capo della lex Aquilia, ritenendo il feto un cavallo, ma preferì un'impostazione che 'non impli- 
volontaria da una donna libera, non è mai stato considerato in epoca classica come un omicidio, in quanto il feto non è sino alla nascita un uomo ${ }^{127}$, sia che lo riteniamo un'entità dotata di una sua autonomia anche durante la gravidanza, un'entità già in rerum natura, sia che lo consideriamo solo una pars matris ${ }^{128}$.

6. L'ipotesi che l'utilizzo da parte di Bruto del quasi rupto possa essere dovuto alla mancanza del contatto corpore viene in qualche modo rafforzato dal fatto che lo stesso sintagma viene utilizzato nello stesso senso all'interno dello stesso frammento tratto dal $18^{\circ}$ libro $\mathrm{ad}$ edictum, nel §24, in cui Ulpiano riporta il parere di Viviano

cava alcuna valutazione forzata della realtà', perchè il feto non è un cavallo in quanto, fino alla nascita, non è un essere autonomo rispetto al corpo della madre.

${ }^{127} \mathrm{Se}$, per il Corbino, non può negarsi che l'aborto comporti la perdita di un'utilità legata alla cosa colpita, lo è però solo come spes, e rappresenta cioè un lucro cessante. Bruto avrebbe, allora, non solo ritenuto già rilevante il danno da lucro cessante ma anche considerato tale un lucro dipendente da un fatto incerto come la nascita e non stimabile anche per la ulteriore incertezza - sesso e caratteristiche individue - del bene considerato. Non si comprenderebbe, per l'autore, come per Quinto Mucio l'aborto potrebbe essere divenuto un evento di sicura rilevanza aquiliana, in quanto la considerabilità del lucro cessante sotto il profilo aquiliano sarebbe stato un problema aperto anche alcuni secoli dopo. E', inoltre, impossibile, per l'autore, che Bruto si sia limitato (senza che il testo vi accenni) ad una parte delle conseguenze materiali del comportamento descritto (la perdita del feto) e Quinto Mucio all'altra (i danni alla madre), essendo tali conseguenze in entrambi i casi necessariamente la perdita del feto (aborto) e le collegate lesioni alla cosa madre. Se Bruto in D. 9, 2, 27, 22 sembra partire dal presupposto che il feto fosse morto o avesse subito dei danni, nel caso, invece, la gestazione si fosse trovata ad uno stadio avanzato, si sarebbe potuto verificare un parto prematuro e il nato sarebbe potuto sopravvivere senza subire alcun danno, così come la madre (parla solo di parto prematuro F.M. DE RoBERTIS, Damnum iniuria datum, Trattazione sulla responsabilità extracontrattuale nel diritto romano con particolare riguardo alla lex Aquilia de damno, Bari 2000, 66; ritiene di recente GALEOTTI, Ricerche I, cit., 244, che il responsum non muterebbe nel caso di un parto prematuro). Anche Quinto Mucio, il quale ritiene che l'oggetto ruptum sia la cavalla, parte dal presupposto, nel caso esaminato, che il feto sia morto o la cavalla abbia, comunque, subito dei danni, ma se il feto fosse, invece, nato vivo, e la madre non avesse riportato altri danni, potrebbe non verificarsi alcun danneggiamento e conseguente danno economico.

${ }^{128}$ La convinzione della dottrina dominante che il feto fosse considerato dai giuristi romani solo una portio mulieris si basa principalmente, come noto, su Ulp. 24 ad ed. D. 25, 4, 1, 1: Ex hoc rescripto evidentissime apparet senatus consulta de liberis agnoscendis locum non habuisse, si mulier dissimularet se praegnatem vel etiam negaret, nec immerito: partus enim antequam edatur, mulieris portio est vel viscerum. post editum plane partum a muliere iam potest maritus iure suo filium per interdictum desiderare aut exhiberi sibi aut ducere permitti, e Pap. 19 quaest. D. 35, 2, 9 pr. - 1: In Falcidia placuit, ut fructus postea percepti, qui maturi mortis tempore fuerunt, augeant hereditatis aestimationem fundi nomine, qui videtur illo in tempore fuisse pretiosior. Circa ventrem ancillae nulla temporis admissa distinctio est nec immerito, quia partus nondum editus homo non recte fuisse dicitur. P. CATALANO, Osservazioni sulla "persona" dei nascituri alla luce del diritto romano (da Giuliano a Teixeira de Freitas), in Rassegna di diritto civile, 1988, I, 45 ss., ora in Diritto e Persone, Studi su origine e attualità del sistema romano, I, Torino 1990, 195 ss., ha, peraltro, sostenuto che i due passi rappresentano solo delle eccezioni, convenientemente motivate, al principio di carattere generale della parità del concepito e del nato. Osservavo in un mio precedente articolo, Conceptus pro iam nato habetur, cit., 217 ss., che i due passi si limitano ad affermare che durante la gravidanza il feto non può essere preso in considerazione riguardo agli effetti di cui ci si sta occupando, e cioè la possibilità che la moglie divorziata possa attivare le procedure del senatusconsultum de liberis agnoscendis dopo aver dissimulato o negato di essere incinta e la possibilità che il figlio della schiava nondum editus possa accrescere l'eredità ai fini dell'applicazione della Falcidia. Ulpiano, con la nota frase partus enim antequam edatur, mulieris portio est vel viscerum, alla quale si è da più parti ritenuto di poter attribuire valore decisivo, afferma semplicemente che il concepito, prima della nascita, non può essere esibito al padre, perché non è materialmente ancora venuto alla luce: solo dopo la nascita, il padre potrà domandare che il figlio exhiberi sibi aut ducere permitti. Non si può, d'altro canto, non tener conto della circostanza che in numerose fonti classiche il concepito è considerato già in rerum natura, e non solo per il suo commodum, come ritenuto dalla dottrina più risalente (si veda per tutti E. ALBERTARIO, Conceptus pro iam nato habetur, in Studi, I, Milano 1933, 1 ss.) Così nel noto D. 1, 5, 26, nel quale Giuliano riferisce il principio qui in utero sunt, in toto paene iure civili intelleguntur in rerum natura esse non solo al concepito da una madre libera catturata dai nemici, ma anche al concepito da un'ancilla furtiva, già considerato in rerum natura durante la gravidanza. Se non si può, dunque, negare che il concepito, non solo da donna libera ma anche da schiava, sia per Giuliano in rerum natura, non si può neppure negare che solo con la nascita il concepito può acquistare determinati diritti. 
- Ulp. 18 ad ed. D. 9, 2, 27, 24: Si navem venaliciarum mercium perforasset, Aquiliae actionem esse, quasi ruperit, Vivianus scribit

Una nave che trasporta venaliciariae merces viene perforata; per Viviano si può concedere l'actio Aquiliae, quasi ruperit. Si discute in dottrina se il rumpere riguardi la nave o le merci; mentre l'Albanese ${ }^{129}$ aveva ritenuto verosimile che l'espressione si riferisse alle merci che, in seguito al buco fatto nella nave, erano andate perdute, per il Musumeci ${ }^{130}$ il danno era stato arrecato direttamente alla nave; per l'autore Viviano potrebbe avere inteso il rumpere come corrumpere, ma potrebbe anche averlo inteso nel senso originario, o perché ai suoi tempi il rumpere non era ancora equiparato al corrumpere, o perché potrebbe seguire ancora l'orientamento di quella minoranza di giuristi che sarebbero rimasti aderenti all'interpretazione tradizionale del rumpere aquiliano: poiché la nave era stata danneggiata, ma non distrutta, anche Viviano avrebbe operato, come Bruto, una forzatura interpretativa, considerando l'azione come se fosse ricompresa nel rumpere aquiliano. Sembra, però, poco probabile che ai tempi di Viviano la condotta di rumpere, per poter essere qualificata tale, dovesse portare alla distruzione del bene e non solo al suo danneggiamento. In tal senso si è espresso anche il Cannata, il quale, pur ritenendo che in origine il terzo caput della lex Aquilia comprendesse solo i casi in cui il bene veniva distrutto, sostiene che già ai tempi di Quinto Mucio esso comprendesse ogni caso di danneggiamento. Più probabile, dunque, che il problema fosse quello del danneggiamento delle merci e non della nave, che, essendo stata perforata, era stata indubbiamente corrupta e, in tal caso, Viviano, e a maggior ragione Ulpiano, avrebbe parlato di rumpere e non di quasi rumpere. Se Viviano si stava occupando dell'esperibilità della lex Aquilia relativamente al danneggiamento o alla distruzione delle merci, come farebbe pensare la precisazione che si tratta di una navis venaliciarum mercium, il quasi ruperit potrebbe essere dovuto alla mancanza di un nesso diretto tra la condotta consistente nella perforazione della nave e il danneggiamento delle merci in essa contenute, e, quindi, alla mancanza, anche in questo caso, del contatto corpore.

Pur non potendoci in questa sede soffermare dettagliatamente sull'esegesi dei singoli passi in cui compare il sintagma quasi ruperit o quasi rupto, a me sembra che con esso si intenda motivare la concessione della tutela aquiliana in casi nei quali la fattispecie non appariva esattamente riconducibile, quale ne fosse di volta in volta la ragione, a quella tipica del rumpere. Il Musumeci aveva ritenuto che Ulpiano, considerando ormai pacifico il rumpere come corrumpere e applicabile il terzo caput della lex anche ai danneggiamenti non distruttivi arrecati a schiavi e pecudes ${ }^{131}$, avrebbe utilizzato il quasi rupto con funzione esplicativa, nel senso di 'in quanto', mentre Bruto, che difficilmente poteva equiparare il rumpere al corrumpere, essendo vissuto in un'epoca abbastanza vicina a quella della emanazione della lex Aquilia, avrebbe utilizzato l'espressione non nel senso di 'in quanto', ma nel senso di 'come se', fin-

\footnotetext{
${ }^{129}$ ALBANESE, Studi, cit., 201 ss.

${ }^{130}$ MusumeCI, Quasi ruperit, cit., 363 ss.

${ }^{131}$ il caso in questione sarebbe rientrato agevolmente nell'ambito di tale caput, perché il pugnus e l'ictus avevano provocato nella schiava e nella cavalla 'una sicura alterazione organica'. Era andato distrutto il feto, ritenuto parte della madre; la schiava e la cavalla avevano, dunque, subito una lesione fisica, un corrumpere, con conseguente danno economico (probabile diminuzione di valore, spese di cura, mancato acquisto dello schiavo o del puledro). Anche il Musumeci aderisce, dunque, alla tesi secondo cui in origine il terzo caput della lex Aquilia avrebbe fatto unicamente riferimento ad azioni che avessero provocato la distruzione delle ceterae res. Successivamente, specialmente in connessione con l'interpretazione, operata dai giuristi, del ruperit nel senso di corruperit, la casisitica che finì per ricadere sotto il regime della lex Aquilia sarebbe risultata assai più ampia, includendo anche i danneggiamenti non distruttivi. Il risultato finale è per il Musumeci che si aveva corruptio di un bene tutte le volte che fosse rimasto danneggiato a causa di una qualsivoglia alterazione materiale, ovvero a causa solo di una sua alterazione funzionale purchè definitiva.
} 
gendo che il comportamento fosse, di per sé, riconducibile al rumpere ${ }^{132}$. Tale opinione si presta all'obiezione che Ulpiano - a meno che non si pensi che abbia utilizzato il quasi solo perché l'aveva trovato in Bruto - avrebbe, allora, dovuto utilizzare il quasi anche negli altri casi in cui faceva riferimento al corrumpere al posto del rumpere; dal momento che le fonti depongono diversamente, non sembra verosimile possa essere questo il motivo dell'utilizzo del quasi in D. 9,2,27,22.

7. Il Corbino, per il quale il rumpere si doveva riferire in origine solo ai danneggiamenti distruttivi e permanenti, ritiene però che il dubbio espresso da Bruto in D. 9, 2, 27, 22 potrebbe essere dovuto al fatto che nell'aborto si avevano fatti lesivi che, se anche distruttivi, erano temporanei, perché la particolare natura della cosa che le subiva, un essere vivente, ne consentiva anche "il riassorbimento' ${ }^{133}$. Bruto non avrebbe esteso il rumpere in corrumpere, ma avrebbe riflettuto sul fatto che il legislatore, accompagnando il verbo rumpere con i verbi urere e frangere, avrebbe mostrato di voler dare rilevanza anche a lesioni come quelle provocate dal fuoco o consistenti in effrazioni che non comportavano necessariamente l'eliminazione fisica della cosa e potevano non determinare una 'irreparabilità materiale' del danno causato: sarebbe rilevata anche la perdita che si verificava quando la cosa, pur conservando esistenza, 'mutava funzione economica'. L'aborto, che per l'autore determina lesioni materiali come le ferite o inabilitanti come lo spossamento, non irreversibili, e dà luogo anche, a causa della perdita del feto, ad un "deprezzamento solo temporaneo della cosa", causa sempre, dunque, lesioni che, a differenza di quelle che derivano dal rumpere (anche nella più lata accezione di corrumpere) sono temporanee, allo stesso modo delle lesioni conseguenza di un urere o frangere che potevano non impedire un ripristino di funzione, talora spontaneo, talora ottenuto attraverso opportuni interventi. La circostanza, di cui nessuno dubita, che le tre condotte di urere frangere rumpere fossero previste nel dettato originario del terzo caput, mi pare mostri, peraltro, che sin dall'inizio non vi era l'intenzione di prendere in considerazione solo i danneggiamenti distruttivi, in quanto non si rilevano differenze tra le condotte di urere frangere e quella di rumpere circa la possibilità di provocare un deterioramento del bene che non consista in una lesione permanente. Inoltre la circostanza che il frangere non provochi necessariamente danni distruttivi sembra avvalorata dal fatto che l'ossis fractio sin dai tempi delle XII tavole può indicare anche un danneggiamento non irreparabile; la spiegazione del Corbino per l'utilizzo del quasi in D. 9, 2, 27, 22 non sembra, pertanto, convincente.

Una spiegazione diversa per il quasi ruptum era stata addotta dal Cannata nell'analisi congiunta di D. 9, 2, 27, 22 col successivo D. 9, 2, 27, 23: et si mulum plus iusto oneravit et aliquid membri ruperit, Aquiliae locum fore, utilizzati da Ulpiano rispettando il diverso modo in cui erano enunciati, in funzione di una conclusione di più vasta portata, per la quale entrambi fornirebbero argomento. La scelta di Bruto di imperniare entrambe le soluzioni sul rumpere sarebbe una scelta consapevole, in quanto egli identifica il membro fratturato come ruptum, quando, secondo la terminologia delle XII Tavole, l'avrebbe dovuto qualificare come fractum $^{134}$ : anche se la zampa del mulo, contrariamente al feto, è una parte integrante del mulo, non ha alcuna traccia di una propria individualità, quel che verrebbe giuridicamente in considerazione sarebbe la ruptio della zampa, cetera res, e non la ruptio del mulo. La considerazione della zampa come una cetera res, che suscita forti perplessità, come già osservato dal Musu-

\footnotetext{
${ }^{132}$ Questa forzatura ermeneutica avrebbe operato direttamente sulla qualificazione dell'azione lesiva, che, grazie ad essa, pur non avendo carattere distruttivo e pur riguardando una schiava ed una pecus, sarebbe stata assimilata alle azioni lesive realmente riconducibili al rumpere aquiliano.

${ }^{133}$ CORBINO, Lex Aquilia, cit., 162.

${ }^{134}$ non si vede, peraltro, perché le XII Tavole in questo caso avrebbero dovuto parlare di os fractum e non di membrum ruptum.
} 
meci ${ }^{135}$, è stata di recente accolta dalla Galeotti ${ }^{136}$, per la quale come pars del mulo, la zampa è 'altro' rispetto all'animale intero, così come il feto è una res altra rispetto alla madre, dunque entrambi sono riconducibili alle ceterae res, le uniche, anche a suo avviso, previste nel dettato originario del terzo caput della lex Aquilia. Il ragionamento di Bruto in D. 9, 2, 27, 22 - 23 può essere, per l'autrice, così ricostruito: il feto è una res altra rispetto alla madre, tanto che la sua ruptio costituisce una lesione di per sé rilevante, valutabile al momento dell'espulsione; giacchè innestato nell'equa o nella mulier, tuttavia il fetus ne costituisce una pars e come tale dovrà essere valutato, a causa della sua natura non commerciabile. La somma da corrispondere al dominus dovrà pertanto essere calcolata misurando l'incidenza che la sua perdita ha avuto sul valore della serva o della pecus. Per quanto riguarda la zampa del mulo, come pars dello stesso, anche essa è altro rispetto all'animale intero, dunque riconducibile alle ceterae res di cui tratta il terzo caput; poiché l'arto (o l'organo) leso può essere valutato economicamente solo come pars rei, in un momento successivo la giurisprudenza avrebbe dato per acquisita la regola secondo la quale rientrava fra i casi contemplati nel terzo caput della legge anche il ferimento delle res se moventes tutelate dal primo. A me pare che il caso della perdita del feto e della rottura della zampa siano diversi, perché il feto può essere separato dalla madre senza che questa ne venga danneggiata, mentre non altrettanto può dirsi per la zampa del mulo, che, diversamente dal feto, è indubbiamente una pars rei.

Conclusioni. Alla fine di questa disamina rimangono sicuramente aperti alcuni interrogativi, in primo luogo riguardo la previsione originaria del terzo caput della lex Aquilia. Si è visto, infatti, che esso, secondo i testi che ci sono pervenuti, prevedeva ogni ceterum damnum: il rumpere frangere urere sia schiavi e pecudes sia cose inanimate, mentre la dottrina oggi maggioritaria lo ritiene limitato ai soli danneggiamenti distruttivi delle ceterae res $^{137}$. Nessuna fonte parla, peraltro, di un'attività interpretativa volta ad estendere il significato di rumpere come distruzione delle ceterae res al danneggiamento di schiavi e pecudes, mentre i passi più risalenti parlano, invece, della possibilità di allargare il significato di rumpere relativo a schiavi e pecudes per comprendervi ipotesi originariamente non previste, come il caso dell'aborto.

Per quanto poi riguarda l'uso in Bruto di quasi rupto e in Quinto Mucio di rumpere (quia equam ruperat), una spiegazione potrebbe forse essere trovata nella circostanza che per Bruto, così come sostengono la Bignardi e il Cannata, l'oggetto ruptum non è la schiava o la cavalla, ma il feto, che al momento della condotta concretantesi nel pugnus o nell'ictus si trovava all'interno del corpo materno, e non poteva essere toccato materialmente, con conseguente mancanza del requisito del contatto corpore. Per Quinto Mucio l'oggetto ruptum, come d'altronde egli afferma espressamente, è, invece, la cavalla, con la quale il contatto corpore si è verificato. Parte della dottrina non ritiene, peraltro, possibile che Bruto considerasse oggetto ruptum il feto in quanto esso sarebbe sempre stato considerato solo una pars matris; è, tuttavia, difficile far rientrare il feto all'interno delle categorie tradizionali dei frutti o delle partes rei. Se durante la gestazione il feto può essere considerato una portio mulieris, nel momento in cui si separa dal corpo della madre appare evidente che non è una pars rei, ma, pur potendosi separare senza danneggiare la madre, non è neppure, per Bruto - la cui opinione prevalse, come è noto, su quella di Manilio e Publio Scevola ${ }^{138}$ - frutto, in quanto in fructu hominis homo esse

\footnotetext{
${ }^{135}$ MUSUMECI, Quasi ruperit, cit., 385 nt. 106.

${ }^{136}$ GALEOTTI, Ricerche, cit., 249.

${ }^{137} \mathrm{La}$ tesi sembra ancora prevalente in dottrina. Di recente CURSI, Iniuria cum damno, cit., 197 ss., ritiene plausibile che fossero originariamente contemplate dal terzo caput solo le distruzioni delle ceterae res, in quanto solo ritenendo che il danneggiamento originariamente dovesse coincidere con la distruzione totale del bene sarebbe giustificabile l'originario computo del risarcimento sull'intero valore della cosa danneggiata nei trenta giorni precedenti.

${ }^{138}$ Quinto Mucio potrebbe aver seguito sul punto le idee del genitore, dal momento che Ulpiano afferma in D. 7,1,68 pr. che sulla vexata quaestio prevalse l'idea di Bruto, ma non dice in quale periodo. V. ARANGIO-RUIZ, Cicerone giurista, in «Marco Tullio Cicerone». Scritti commemorativi pubblicati nel bimillenario della morte, Roma 1961, 1
} 
non potest. Se intendiamo in fructu hominis nel senso di 'in ciò che viene prodotto per l'uomo', la motivazione andrebbe riferita solo agli esseri umani, ma se letta nel senso di 'nel frutto della schiava' sembra presupporre una differenza ontologica tra il frutto e la cosa madre che lo produce, il che dovrebbe indurre ad escludere la natura di frutto non solo nei parti della schiava, ma anche nei parti animali ${ }^{139}$. Anche sul fetus pecudis, secondo parte della dottrina, sarebbe, infatti, esistita una quaestio relativamente alla sua spettanza al fructuarius o al nudus dominus, e dunque alla sua natura di frutto, quaestio che sarebbe stata risolta solo da Sabino e Cassio, come riferisce Ulpiano in D. 7,1,68,1: Fetus tamen pecorum Sabinus et Cassius opinati sunt ad fructuarium pertinere. Il tamen di D. 7, 1, 68, 1, insieme all'etiam di Gai. 2 rer. cott. D. 22, 1,

ss., ora in Scritti, IV, Napoli 1977, 269 ss., seguito da F. STURM, Zur ursprönglichen Funktion der actio Publiciana, in «RIDA» 9 (1962) 404 ss., riteneva la controversia ancora aperta ai tempi di Cicerone (de fin. 1,4,12). Di diverso avviso A. WATson, The Law of Property in the Later Roman Republic, 1968, 215, e M. TALAMANCA, Costruzione giuridica e strutture sociali fino a Quinto Mucio, in Società romana e produzione schiavistica, III, Bari 1981, 319320 nt. 68, il quale osserva che se il dissenso fosse continuato in tempi più recenti, l'oratore si sarebbe riferito a giuristi più vicini, e la citazione di Bruto ad opera di Ulpiano, per quanto mediata, «sembra indicare, anch'essa, nel senso che la svolta decisiva si fosse con lui avuta». E'stata invece avanzata da J. LINDERSKI, Partus ancillae». A «vetus quaestio» in the Light of a New Inscription, in «Labeo» 33 (1987) 192 ss., l'ipotesi che l'opinione di Scevola e Man1 lio fosse ancora prevalente ai tempi di Augusto. L'Autore si basa su un'iscrizione funeraria trovata a Regium, dove era stata relegata Giulia, la figlia di Augusto, condannata, come è noto, per adulterio: C. Iulius Iuliae divi Aug(usti) f(iliae) 1(ibertus) Celos (si)bi et C. lulio lul(iae divi) Aug(usti) f(iliae) 1(iberto) Thiaso patr(i sexvir(o) a)ug(ustali) (et iu)liae divae Au(guslae 1(iberlae)) malr(i ex testamen(to). Mentre gli schiavi Thiaso e Celos vengono definiti liberti di Giulia, la madre di Celos viene detta liberta della diva Augusta, cioè Livia. Il Lindersky ipotizza che Giulia potesse avere l'usufrutto sulla schiava, che viveva nella sua familia; il figlio di tale schiava sarebbe così spettato alI'usufruttuaria, Giulia, il che proverebbe che l'opinione di Scevola e Manilio che il partus ancillae fosse frutto e quindi spettasse all'usufruttuaria era ancora prevalente a quei tempi. M. TALAMANCA, Pubblicazioni pervenute alla direzione, in «BIDR» 90 (1987) 593 s., ritiene che l'iscrizione di Regium non faccia alcuna luce sull'argomento, in quanto l'opinione del Linderski si basa su 'arbitrarie assunzioni di fatti' e 'su alcuni equivoci relativi alla valutazione tecnico-giuridica degli stessi'. Non si può, infatti, affermare, come fa il Linderski, che la schiava rimanesse giuridicamente una schiava di Livia, 'but as she lived in Julia's household Julia enjoyed the usufruct of that ancilla', perché in questo modo si inventa 'un nuovissimo modo di costituzione di questo diritto reale parziario'. Ha dissentito dall'opinione del Linderski anche A. WATSON, Partus ancillae and a recent Inscription from Regium, in «Labeo» 38 (1992) 335 ss., il quale ha ritenuto non degna di fede l'iscrizione in quanto predisposta da uno schiavo che non era in grado di cogliere le sottigliezze giuridiche legate al caso. L'autore contesta al Linderski di non aver tenuto conto del fatto che perché Giulia, in potestate patris, potesse liberare gli schiavi facenti parte del suo peculium era necessario il consenso del padre e, anche ammettendo che questo vi fosse stato, Celos e Thiaso sarebbero divenuti liberti di Augusto e non di Giulia. Il Watson è del parere che Celos, privo di adeguate conoscenze giuridiche, ritenesse erroneamente sé e il padre, che di fatto erano stati schiavi di Giulia e da lei erano stati liberati, suoi liberti, e correttamente la madre, che di Livia era era stata schiava e da questa era stata liberata, liberta di Livia. Sembra invece concordare col Linderski P. A. VANDER WAERT, Philosophical Influence on Roman Jurisprudence? Tbe Case of Stoicism and natural Law, in «ANRW» II.36.7, Berlin-New York 1994, 4851 ss., in part. 4857, nt. 21: «but Jerzy Linderski has now convincingly argued that the position of Mucius and Manilius was in effect in Cicero's day». Dopo aver ritenuto verosimile che la posizione di Bruto sia in linea di massima prevalsa sin dal tempo della disputa, osserva F. ZuCCOTTI, «Fruges fructusque» (studio esegetico su D. 50,16,77), Per una ricerca sulle origini della nozione di frutto, Padova 2000, 95, nt. 152 (v. anche ID., Partus ancillae in fructu non est, in Antecessori oblata. Cinque studi inediti dedicati ad Aldo Dell'Oro, Padova 2001, 185 ss.), che è tuttavia significativo che «nel silenzio del nudo proprietario, il partus ancillae potesse essere trattato come proprio dal fructuarius e che anzi nell'inazione di questi avrebbe potuto venire ritenuta valida da un punto di vista sociale una manomissione di fatto posta in essere dalI'usufruttuario che si comportasse come dominus, dato che, come è ovvio, la situazione di diritto sottesa a tale fattispecie va in ogni caso fatta valere e che, nella perdurante assenza di una reazione del titolare, con il trascorrere del tempo la realtà di fatto può finire col prevalere: per tal verso, dal punto di vista che qui interessa, non è affatto irrilevante che, in concreto, il figlio dell'ancilla potesse di regola rimanere con essa presso il fructuarius, trattato da questi e considerato da tutti come suo servus, quantomeno fructuarius».

${ }^{139}$ Così M. KASER, Partus ancillae, in «ZSS» 75 (1958) 157 ss., il quale osserva che Ulpiano col tamen considera non del tutto "folgerichtig" che Sabino e Cassio abbiano equiparato agli effetti dell'usucapione i nati animali ai frutti: 'Die erste Begründung, die, obwohl sie Ulpian als seine eigene Aussage formuliert, auf Brutus zurückgehen könnte, scheint einen Fruchtbegriff zu unterstellen, der es nicht zuläßt, da $\beta$ die Frucht von gleicher Gattung ist wie der Träger, der sie hervorbringt. Hiernach dürfte auch das Tierjunge nicht zu den Früchten gerechnet werden; und in der Tat empfindet es Ulpian als nicht ganz folgerichtig (tamen), da $\beta$ die Begründer der sabinianischen Schule die Tierjungen im Fall des Nießbrauchs den Früchten gleichgehalten haben'. 
28 pr.: In pecudum fructu etiam fetus et sicut lac et pilus et lana, secondo parte della dottrina potrebbe rappresentare un indizio dell'esistenza di perplessità anche sulla qualificazione dei nati animali come frutti ${ }^{140}$.

Non si può, pertanto, escludere, se si legge l'affermazione secondo cui il partus ancillae non è frutto perché in fructu hominis homo esse non potest nel senso che tra frutto e cosamadre deve esistere una differenza ontologica, che Bruto potesse da questo punto di vista accomunare nati da schiava e nati animali ${ }^{141}$, non considerandoli entrambi frutti. Ma la circostanza che sia il partus ancillae sia il fetus pecudis vengono espulsi e separati dalla madre senza che la madre ne venga danneggiata (in nessuno dei nostri passi si accenna infatti a ferite della madre), determina problemi anche in ordine ad un'integrale applicazione delle regole giuridiche elaborate in tema di pars rei. Mentre è all'interno del corpo materno, il feto ne è, però, parte, il che rende possibile che Bruto, considerandolo l'oggetto ruptum, abbia usato il quasi in quanto, trovandosi il feto al momento del pugnus o ictus all'interno del corpo materno, non si era con esso realizzato il contatto corpore.

Recebido em: 15 out. 2017.

Aceito em: 12 fev. 2018.

${ }^{140}$ Già G.E. HeIMBACH, Die Lehre von der Frucht nach den gemeinen, in Deutschland geltenden Rechten, Leipzig 1843, 11 ss., osservava che la controversia sui nati animali fu risolta nel senso che i nati animali, così come gli altri frutti animali, dovessero appartenere all'usufruttuario, soluzione che venne accettata sul!'autorità di Sabino e Cassio: ci si vide, così, costretti ad aggiungere i nati ai già riconosciuti tipi di frutto degli animali; H. GOPPERT, Uber die organzischen Erzeugnisse. Eine Untersuchung aus dem romischen Sachenrechl, Halle 1869, parlava di una «Unsicherheit» sulla classificazione dei nati animali; G.F. PUCHTA, Cursus der Institutionen ${ }^{9}$, Leipzig 1881, riteneva sussistente fra i più antichi giuristi una controversia riguardante la natura di frutto dei parti, anche animali, sostenendo alcuni che se si applicava al fetus pecorum la qualifica di frutto, altrettanto si dovesse fare anche per il partus ancillae. Più di recente M. Scarlata FAZIO, s.v. Frutti (dir. rom.) in «ED», XVIII, Milano 1969, 191 ss., in part. 194, osserva che l'etiam di D. 22, 1, 28 pr. induce a pensare che sia esistita una perplessità sulla qualificazione di frutti dei nati animali, risolta in un'epoca non roppo anteriore a Gaio, che con l'etiam ancora la ricorda; J. FILIP-FRÖSCHL, Partus et fetus et fructus. Bemerkungen zur rechtlichen Behandlung der Tierjungen bei den Romern, in Ars boni et aequi: Festschrift für Wolfgang Waldstein zum 65. Geburtstag, Stuttgart 1993, 99 ss., ritiene che da come si esprime Ulpiano in D. 7, 1, 68, 1 si possa desumere che la questione discussa nel principium fosse riferitaanche ai nati animali, che non sono trattati come gli altri frutti, ma sempre citati separatamente. Per R. CARDILLI, La nozione giuridica di fructus, Napoli 2000, 97 ss., pur essendo stata risolta la controversia da Sabino e Cassio, non mancherebbero strascichi nella giurisprudenza successiva, come dimostrerebbero il tamen di Ulpiano, l'etiam di Gaio, gli elenchi di Gai. sing. de form. hyphoth. D. 20,1,15 pr.: Et quae nondum sunt, futura tamen sunt, hypothecae dari possunt, ut fructus pendentes, partus ancillae, fetus pecorum et ea quae nascuntur... e le testimonianze come Pap. 7 resp. D. 22,1,8: Equis per fideicommissum relictis post moram fetus quoque praestabitur ut fructus, sed fetus secundus ut causa, sicut partus mulieris.

${ }^{141}$ Pur considerando solo possibile l'ipotesi della necessità di una differenza ontologica fra nato e cosa madre per la qualificazione di un bene come frutto, e pur concordando col Talamanca sul rilievo che, se Bruto avesse inteso formulare tale regola, il suo modo di esprimersi sarebbe stato inadeguato, ritengo che anche la lettura di in fructu hominis homo esse non potest nel senso di «in ciò che viene prodotto per l'uomo non vi può essere un uomo» desti, dal punto di vista letterale, altrettante perplessità. 